NASA/TM-2002-210732

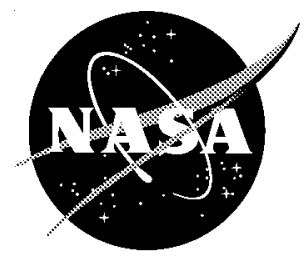

\title{
Induced Moment Effects of Formation Flight Using Two F/A-18 Aircraft
}

Jennifer L. Hansen and Brent R. Cobleigh

NASA Dryden Flight Research Center

Edwards, California

August 2002 


\section{The NASA STI Program Office...in Profile}

Since its founding, NASA has been dedicated to the advancement of aeronautics and space science. The NASA Scientific and Technical Information (STI) Program Office plays a key part in helping NASA maintain this important role.

The NASA STI Program Office is operated by Langley Research Center, the lead center for NASA's scientific and technical information. The NASA STI Program Office provides access to the NASA STI Database, the largest collection of aeronautical and space science STI in the world. The Program Office is also NASA's institutional mechanism for disseminating the results of its research and development activities. These results are published by NASA in the NASA STI Report Series, which includes the following report types:

- TECHNICAL PUBLICATION. Reports of completed research or a major significant phase of research that present the results of NASA programs and include extensive data or theoretical analysis. Includes compilations of significant scientific and technical data and information deemed to be of continuing reference value. NASA's counterpart of peer-reviewed formal professional papers but has less stringent limitations on manuscript length and extent of graphic presentations.

- TECHNICAL MEMORANDUM. Scientific and technical findings that are preliminary or of specialized interest, e.g., quick release reports, working papers, and bibliographies that contain minimal annotation. Does not contain extensive analysis.

- CONTRACTOR REPORT. Scientific and technical findings by NASA-sponsored contractors and grantees.
- CONFERENCE PUBLICATION. Collected papers from scientific and technical conferences, symposia, seminars, or other meetings sponsored or cosponsored by NASA.

- SPECIAL PUBLICATION. Scientific, technical, or historical information from NASA programs, projects, and mission, often concerned with subjects having substantial public interest.

- TECHNICAL TRANSLATION. Englishlanguage translations of foreign scientific and technical material pertinent to NASA's mission.

Specialized services that complement the STI Program Office's diverse offerings include creating custom thesauri, building customized databases, organizing and publishing research results...even providing videos.

For more information about the NASA STI Program Office, see the following:

- Access the NASA STI Program Home Page at http://www.sti.nasa.gov

- E-mail your question via the Internet to help@sti.nasa.gov

- Fax your question to the NASA Access Help Desk at (301) 621-0134

- Telephone the NASA Access Help Desk at (301) 621-0390

- Write to:

NASA Access Help Desk

NASA Center for AeroSpace Information 7121 Standard Drive Hanover, MD 21076-1320 
NASA/TM-2002-210732

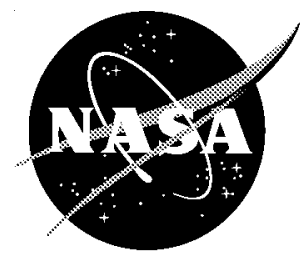

\section{Induced Moment Effects of Formation Flight Using Two F/A-18 Aircraft}

Jennifer L. Hansen and Brent R. Cobleigh NASA Dryden Flight Research Center

Edwards, California

National Aeronautics and

Space Administration

Dryden Flight Research Center

Edwards, California 93523-0273

August 2002 


\section{NOTICE}

Use of trade names or names of manufacturers in this document does not constitute an official endorsement of such products or manufacturers, either expressed or implied, by the National Aeronautics and Space Administration.

Available from the following:

NASA Center for AeroSpace Information (CASI)

7121 Standard Drive

Hanover, MD 21076-1320

(301) 621-0390
National Technical Information Service (NTIS) 5285 Port Royal Road Springfield, VA 22161-2171

(703) $487-4650$ 


\title{
INDUCED MOMENT EFFECTS OF FORMATION FLIGHT USING TWO F/A-18 AIRCRAFT
}

\author{
Jennifer L. Hansen $^{*}$ and Brent R. Cobleigh ${ }^{\dagger}$ \\ NASA Dryden Flight Research Center \\ Edwards, California
}

\begin{abstract}
$\underline{\text { Abstract }}$
Previous investigations into formation flight have shown the possibility for significant fuel savings through drag reduction. Using two F/A-18 aircraft, NASA Dryden Flight Research Center has investigated flying aircraft in autonomous formation. Positioning the trailing airplane for best drag reduction requires investigation of the wingtip vortex effects induced by the leading airplane. A full accounting of the vortex effect on the trailing airplane is desired to validate vortex-effect prediction methods and provide a database for the design of a formation flight autopilot. A recent flight phase has mapped the complete wingtip vortex effects at two flight conditions with the trailing airplane at varying distances behind the leading one. Force and moment data at Mach 0.56 and an altitude of $25,000 \mathrm{ft}$ and Mach 0.86 and an altitude of $36,000 \mathrm{ft}$ have been obtained with $20,55,110$, and $190 \mathrm{ft}$ of longitudinal distance between the aircraft. The moments induced by the vortex on the trailing airplane were well within the pilot's ability to control. This report discusses the data analysis methods and vortex-induced effects on moments and side force. An assessment of the impact of the nonlinear vortex effects on the design of a formation autopilot is offered.
\end{abstract}

\section{$\underline{\text { Nomenclature }}$}

$\begin{array}{ll}\text { AFF } & \text { Autonomous Formation Flight } \\ a_{y} & \text { lateral acceleration, } g\end{array}$

\footnotetext{
*Aerospace Engineer; Member.

†Aerospace Engineer; Senior Member.

Copyright $\triangle 2002$ by the American Institute of Aeronautics and Astronautics, Inc. No copyright is asserted in the United States under Title 17, U.S. Code. The U.S. Government has a royalty-free license to exercise all rights under the copyright claimed herein for Governmental purposes. All other rights are reserved by the copyright owner.

Notice: the use of trade names or names of manufacturers in this document does not constitute an official endorsement of such products or manufacturers, either expressed or implied, by the National Aeronautics and Space Administration.
}

\begin{tabular}{|c|c|}
\hline$b$ & F/A-18 wingspan $(37.5 \mathrm{ft})$ \\
\hline $\bar{c}$ & chord, ft \\
\hline$C$ & coefficient of force or moment \\
\hline$C_{l}$ & coefficient of rolling moment \\
\hline$C_{m}$ & coefficient of pitching moment \\
\hline$C_{n}$ & coefficient of yawing moment \\
\hline$C_{Y}$ & coefficient of side force \\
\hline$g$ & unit of gravity \\
\hline GPS & global positioning system \\
\hline $\mathrm{h}$ & pressure altitude, $\mathrm{ft}$ \\
\hline$i$ & integer \\
\hline$I_{X}, I_{Y}, I_{Z}$ & $\begin{array}{l}\text { moments of inertia about the } X, Y \text {, and } Z \\
\text { vehicle reference axes, respectively; } \\
\text { slug- } \mathrm{ft}^{2}\end{array}$ \\
\hline \multicolumn{2}{|c|}{$I_{X Y}, I_{X Z}, I_{Y Z}$ products of inertia, slug-ft ${ }^{2}$} \\
\hline M & Mach number \\
\hline$m$ & mass, slug \\
\hline$M_{X}, M_{Y}, M_{Z}$ & $\begin{array}{l}\text { moments about the } X, Y \text {, and } Z \text { vehicle } \\
\text { reference axes, respectively; ft-lbf }\end{array}$ \\
\hline$p, q, r$ & $\begin{array}{l}\text { components of angular velocity about the } \\
X, Y \text {, and } Z \text { vehicle reference axes, } \\
\text { respectively; } \mathrm{rad} / \mathrm{sec}\end{array}$ \\
\hline$\dot{p}, \dot{q}, \dot{r}$ & $\begin{array}{l}\text { components of angular acceleration about } \\
X, Y \text {, and } Z \text { vehicle reference axes, } \\
\text { respectively; } \mathrm{rad} / \mathrm{sec}^{2}\end{array}$ \\
\hline$q_{\infty}$ & dynamic pressure, $\mathrm{lbf} / \mathrm{ft}^{2}$ \\
\hline$S$ & wing area, $\mathrm{ft}^{2}$ \\
\hline SG & smoke generator \\
\hline TAS & true airspeed \\
\hline$X$ & longitudinal position, $b$ \\
\hline$Y$ & lateral position, $b$ \\
\hline
\end{tabular}




$$
\begin{array}{ll}
Z & \text { vertical position, } b \\
\alpha & \text { angle of attack, deg } \\
\beta & \text { angle of sideslip, deg } \\
\gamma & \text { flightpath angle, deg } \\
\theta & \text { pitch angle, deg } \\
\psi & \text { heading angle, deg }
\end{array}
$$

$\underline{\text { Subscripts }}$

$$
\begin{array}{ll}
\text { lead } & \text { leading airplane } \\
\text { trail } & \text { trailing airplane }
\end{array}
$$

\section{$\underline{\text { Introduction }}$}

For thousands of years, birds have taken advantage of the aerodynamic benefits obtained by flying in formation. The traditional " $V$ " formation-flown by many species of birds, including gulls, pelicans, and geese-allows each of the following birds to fly in the wingtip vortex-induced upwash flow field that exists just to the side of the bird immediately ahead in the formation. The result for the individual birds is a lower induced drag, allowing for a reduction in the energy required to maintain a given speed. A recent study ${ }^{1}$ reported energy savings between 11 and 14 percent for pelicans flying in formation, based on a reduction in heart rate. This power reduction applies to each of the birds aft of the leader. For migratory birds, formation flight extends the range of the formation birds beyond the range of solo birds.

The Autonomous Formation Flight (AFF) project was formed in an attempt to extend this beneficial relationship to aircraft. Led by the NASA Dryden Flight Research Center (Edwards, California), the project has used F/A-18 aircraft (McDonnell Douglas Corporation, now The Boeing Company, St. Louis, Missouri; and Northrop Corporation, now Northrop Grumman, Newbury Park, California) to demonstrate the technologies necessary to perform extended close formation flight to reduce fuel usage or extend the range of a system of aircraft. The AFF team has included Boeing, the University of California at Los Angeles, and the NASA Ames Research Center (Moffett Field, California).

Although fighter aircraft have been used for the technology demonstration, formation flight drag reduction could be of most interest to improve cruise performance of larger military or commercial aircraft. System studies have shown that a 10-percent drag reduction for a commercial airliner conducting a daily
Los Angeles-to-New York roundtrip results in reduced fuel usage in excess of $\$ 500,000$ for each airplane each year, as well as emission reductions of carbon dioxide and oxides of nitrogen of 10 percent and 15 percent, respectively.

One byproduct of flying in the vicinity of the highly nonlinear wingtip vortex is the torque imparted on the trailing airplane. As figure 1 shows, when positioned in "V" formation on the right side-where the trailing airplane wingtip is near the leading airplane wingtip vortex - the trailing airplane left wingtip is receiving most of the vortex-induced upwash. This upwash produces greater lift on the left wing, which tends to roll the trailing airplane away from the leading one. This rolling moment must be counteracted by the pilot or station-keeping autopilot to maintain the formation.

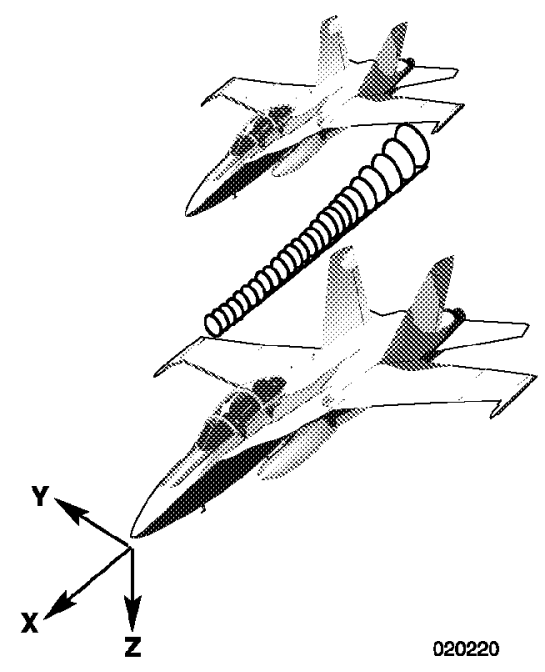

Figure 1. Formation axes system.

As the trailing airplane moves further left, the downwash side of the vortex from the leading airplane begins to affect the left wing while the upwash side influences the fuselage and right wing. The influence of the downwash starts to reduce the magnitude of the rolling moment to the right. Eventually, the resulting rolling moment on the trailing airplane has the opposite sign of and a larger magnitude than the rolling moment of only one wingtip aligned with the leading airplane wingtip vortex.

In fact, the vortex flow field induces changes to all of the forces and moments on the trailing airplane, as shown in subsequent plots. Pitching moment changes can be positive or negative, depending on airplane 
position within the vortex flow field. Because the peak rolling moment occurs at the position of optimum drag reduction (13-percent wing overlap ${ }^{2}$ ), the trim drag must be taken into account. In addition to the benefits for the trailing airplane, the leading airplane experiences no negative effects as a result of formation flight.

The highly nonlinear vortex flow field significantly increases the pilot workload and reduces the ability of the pilot to precisely maintain the optimum position for maximum drag reduction. Therefore, any realistic long-duration use of precise formation flight requires the use of a station-keeping autopilot. The autopilot must be able to track a commanded relative position or trajectory in the presence of gust disturbances and unsteady vortex effects. The design of a formation flight autopilot must be sensitive to the highly nonlinear, position-dependent vortex flow field; and requires an accurate mathematical model of the induced aerodynamic effects as a function of relative position and flight condition.

In support of the AFF autopilot design, a flight test program has been conducted to map the formation flight effects on two F/A-18 aircraft at four nose-to-tail separation distances and two flight conditions. Forces and moments have been calculated during pilot-in-the-loop, constant relative-position test points and compared with data measured outside the vortex influence. A database model of the rolling, pitching, and yawing moments and the side force increments caused by the vortex has been assembled. This database will be used-along with similar models for the lift and drag - to validate vortex-effect prediction codes, refine the formation flight autopilot design, and conduct accurate formation flight simulation studies.

\section{Experiment Description}

To acquire a complete map of the vortex effects on the trailing airplane, stable flight test points were defined over a "grid" in the lateral-vertical $(Y-Z)$ plane (figs. 1-2). The trailing airplane pilot flew the grid of points at four longitudinal distances behind the leading airplane. A description of and the rationale for the grid points, four longitudinal distances, and two flight conditions are presented herein.

In a compromise between mapping resolution and flight test time, the test points were spaced one-eighth of an F/A-18 wingspan (b) apart, or approximately $4.7 \mathrm{ft}$. The grid extended from $0.50 \mathrm{~b}$ high to $0.50 \mathrm{~b}$ low in the vertical axis, and from $0.25 b$ of wingtip separation to
$0.50 b$ of wingtip overlap in the lateral direction. Figure 2 shows a graphical depiction of the test matrix.

The longitudinal positions were also referenced to $b$, and were selected to match previously published experimental studies. ${ }^{3}$ When the location for optimum drag reduction was identified, a finer resolution of mapping was used in that area. Because the pilots had no indication in the cockpit of longitudinal position, the nose-to-tail distance was monitored in the control room and maintained by the pilot through radio calls. This monitoring was done to maintain both safety of flight and data quality.

The longitudinal positions were set at $2.0 \mathrm{~b}, 3.0 \mathrm{~b}$, $4.0 \mathrm{~b}$, and $6.5 \mathrm{~b}$ (measured nose to nose); or approximately 20-, 55-, 110-, and 190-ft nose to tail, respectively. Because of the origin of the formation axes system (at the nose of the leading airplane), the $Y$ and $Z$ positions were positive out the right wing and down, respectively. A $Y$ position of $0.25 b$ wingtip separation corresponds to approximately $10 \mathrm{ft}$ between wings, whereas a $Y$ position of $-0.25 b$ wingtip separation corresponds to approximately $10 \mathrm{ft}$ of wingtip overlap. The $Z$ position was also nondimensionalized by $b$, and although the formation axes system dictates that $Z$ is positive down, the vertical positions within the test matrix are referred to as positive when the trailing airplane is above the leading airplane.

As previously described, the vortex effects from this series of flight tests were also to be used to validate preexisting data from vortex-effect prediction codes. ${ }^{4}$ To allow direct comparisons with existing analytic data acquired at a flight condition of Mach 0.56 and an altitude of $25,000 \mathrm{ft}$, extensive flight data were acquired at the same subsonic condition. Because one possible future application of AFF is for transport aircraft, flight data were also acquired at a transonic condition of Mach 0.86 and an altitude of $36,000 \mathrm{ft}$, which is representative for that class of vehicle. Note that each flight condition has a different flap setting that altered the lift distribution of the wing, and therefore the properties of the vortex.

The AFF research has been accomplished using two NASA Dryden F/A-18 research aircraft. The aircraft flew in clean configurations without stores for most testing. When in-flight flow visualization was desired, smoke generators were attached to a single wingtip on each airplane. The lead airplane is a two-seat, preproduction F/A-18 airplane; a single-seat F/A-18 airplane was used as the trailing airplane. Both aircraft have been instrumented with real-time angular rates and 


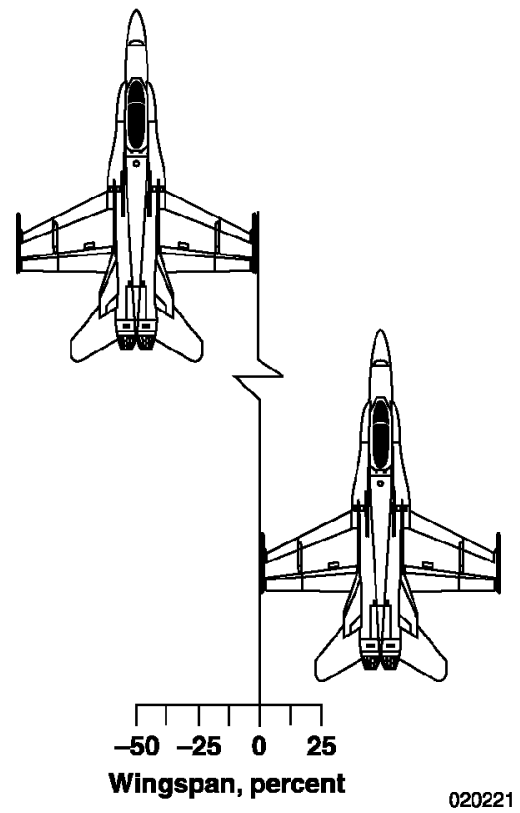

a. Relative lateral position.

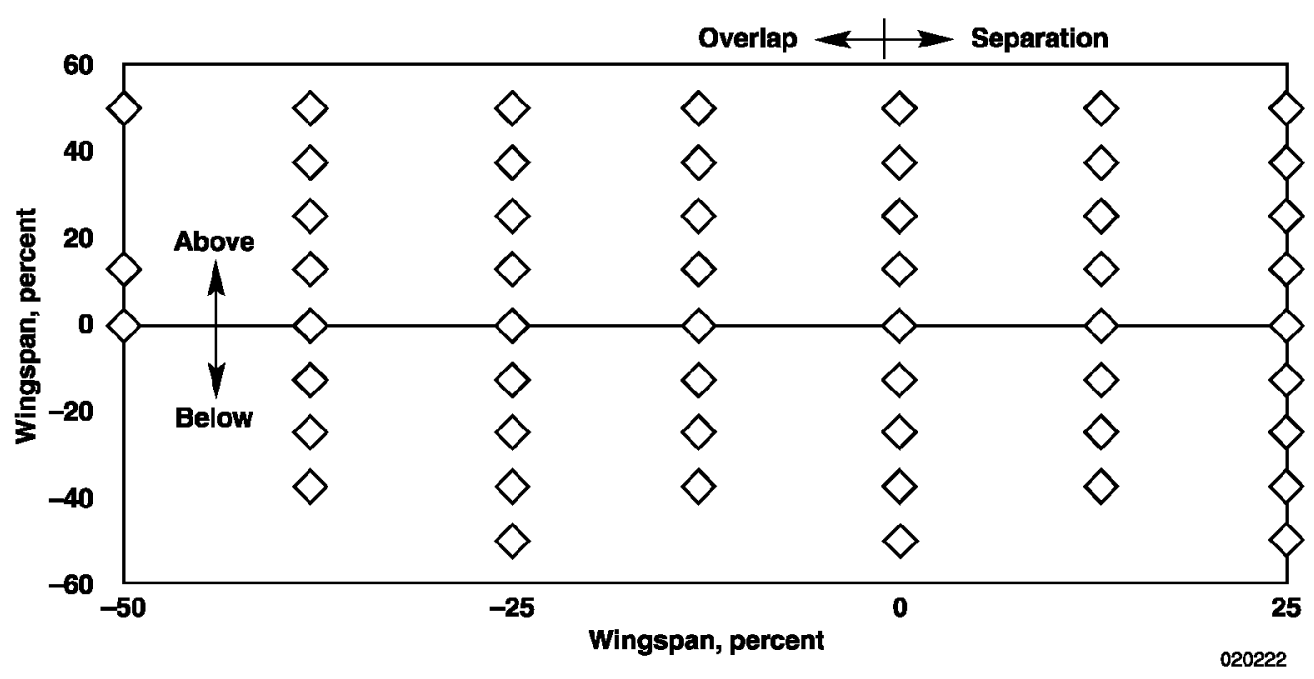

b. Test point matrix.

Figure 2. Vortex mapping grid. 
linear accelerations; and the aircraft bus data include such data as control surface positions, fuel level readings, stick positions, and engine data. Because accurate relative-position data are crucial to the experiment, both aircraft have been equipped with a relative-position global positioning system (GPS). ${ }^{5}$ This system drove the guidance needles display used by the pilot in the trailing airplane to get into and maintain relative position with the leading airplane.

When at the flight condition, the pilot of the leading airplane engaged the standard F/A-18 autopilots to hold altitude, heading, and velocity. The pilot of the trailing airplane flew into the desired position behind the leading airplane by following the GPS-driven target display $^{5}$ in the cockpit. This target position was selected by the pilot of the trailing airplane using a cockpit switch. The display consists of two needles usually used for an instrument landing system on a carrier-borne aircraft. The pair of needles guided the pilot to the target position, which was generally behind and to the right of the leading airplane. Using this target display system, the pilot maintained position for $30 \mathrm{sec}$. The GPS accuracy was on the order of $2.5 \mathrm{ft}$, plus or minus a standard deviation of 2. Postflight analysis of the data taken during this time was used to calculate the vortex-induced effects on the trailing airplane.

\section{$\underline{\text { Methodology }}$}

The incremental coefficients caused by vortex influence were calculated as the difference between the free-flight coefficients (assuming no vortex interaction) and the actual flight-measured vortex coefficients (measured while the airplane was positioned within the vortex influence) at a particular flight condition. Figure 3 shows the data analysis process. A number of baselines, or vortex-free stabilized points, were periodically completed throughout each flight. The baselines assessed the effects of the asymmetries of the smoke generators. These asymmetries were accounted for in the force and moment calculations.

\section{Free-Flight Model Calculations}

The free-flight model was calculated using the F/A-18 aerodynamic database, which is a function of control surface deflections; angle of attack $(\alpha)$; angular velocities corrected to the reference point; and flight conditions to determine the coefficients of rolling, pitching, and yawing, moments and side force $\left(C_{l}, C_{m}\right.$, $C_{n}$, and $C_{Y}$, respectively). These flight data were used as input to perform table lookups of the free-flight aerodynamic coefficients. Because of the vortex influence on the angle-of-attack vanes of the trailing

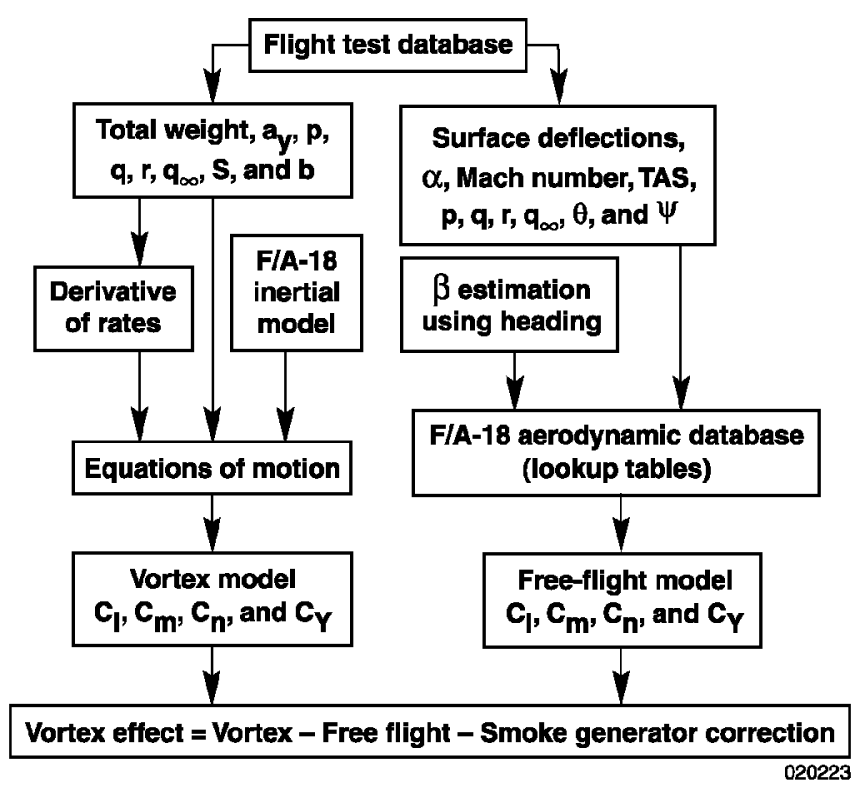

Figure 3. Data analysis methodology 
airplane, approximating $\alpha$ and angle of sideslip $(\beta)$ was necessary. The $\alpha$ of the trailing airplane was calculated using flightpath angle $(\gamma)$ and pitch angle $(\theta)$ and assuming the following:

$$
\begin{gathered}
\gamma_{\text {lead }}=\gamma_{\text {trail }}, \\
\text { and } \\
\gamma=\theta-\alpha
\end{gathered}
$$

so subsequently,

$$
\alpha_{\text {trail }}=\alpha_{\text {lead }}+\theta_{\text {trail }}-\theta_{\text {lead }} .
$$

Because a reliable sideslip parameter was not available on the trailing airplane, the $\beta$ was estimated as the difference in heading angle, $\psi$, between the two aircraft. The estimated $\beta$ was calculated as follows:

$$
\beta_{\text {trail }} \approx \psi_{\text {trail }}-\psi_{\text {lead }}
$$

The necessary parameters were input into the F/A-18 aerodynamic database to get the resulting $C_{l}, C_{m}, C_{n}$, and $C_{Y}$ for the free-flight model.

\section{Vortex Calculations}

The flight-measured vortex model was calculated using the following closed-form equations: 6,7

$$
\begin{aligned}
C_{l} & =\sum \frac{M_{X}}{q_{\infty} S b} ; \\
C_{m} & =\sum \frac{M_{Y}}{q_{\infty} S \bar{c}} ; \\
C_{n} & =\sum \frac{M_{Z}}{q_{\infty} S b} ; \\
C_{Y} & =a_{y} \frac{m g}{q_{\infty} S} .
\end{aligned}
$$

Assuming the airplane is symmetric about the longitudinal-vertical $(X-Z)$ plane,

$$
I_{X Y}=I_{Y Z}=0
$$

and the total moment equations simplify to

$$
\begin{aligned}
& \sum M_{X}=\dot{\mathrm{p}} I_{X}-\dot{\mathrm{r}} I_{X Z}+q\left(r I_{Z}-p I_{X Z}\right)-r q I_{Y} \\
& \sum M_{Y}=\dot{q} I_{Y}+r\left(p I_{X}+r I_{X Z}\right)-p\left(r I_{Z}-p I_{X Z}\right) \\
& \sum M_{Z}=\dot{r} I_{Z}-\dot{p} I_{X Z}+p q I_{Y}-q\left(p I_{X}-r I_{X Z}\right)
\end{aligned}
$$

Flight-measured data were used for $p, q, r, q_{\infty}$, and $a_{y}$; and the angular accelerations were calculated by differentiating the measured angular rates with respect to time. The vortex effect on the trailing airplane then was calculated as the mean difference between the vortex and free-flight models over the steady-state test point:

$$
=\frac{\sum_{i=1}^{n}\left(\text { Vortex } C_{i}-\text { Free-flight } C_{i}\right)}{n},
$$

where $n$ is the number of data points.

Figure 4 shows an example plot of the data taken during a $30-\mathrm{sec}$ test point. These time-averaged moment and force influences were plotted against true lateral position at each vertical position in the test point grid.

\section{$\underline{\text { Results and Discussion }}$}

Although the vortex grid was mapped at four nose-to-tail distances and two flight conditions, only the data corresponding with conditions and nose-to-tail distances of optimum drag reduction are discussed herein. Extrapolation of the data assumed that the vortex-induced effects on the trailing airplane asymptotically approached zero as wingtip separation increased. Each plot has an incremental moment or force plotted against lateral position. Each line on the plot represents a different vertical position.

One source of possible error is GPS accuracy (on the order of $2.5 \mathrm{ft}$, plus or minus a standard deviation of 2.) In addition, different flying styles of the five pilots might have influenced the data, and certain positions in the formation were more difficult to fly because of the lack of a good visual reference (for example, very high vertical positions $(0.50 \mathrm{~b})$, or positions with nose-to-tail distances greater than $110 \mathrm{ft}$, or a combination thereof).

\section{5-ft Nose-to-Tail Separation at the Subsonic Condition}

The aircraft were flown with a nose-to-tail separation of $55 \mathrm{ft}$ at a subsonic flight condition of Mach 0.56 and an altitude of 25,000 ft. The following sections discuss incremental rolling, yawing, and pitching moment and side force.

\section{Incremental Rolling Moment}

As the trailing airplane lateral position changed from separation to overlap, the vortex effects produced an increasing right rolling moment increment (fig. 5). The maximum rolling moment increment occurred at the $-0.13 \mathrm{~b}$ lateral test point. At $-0.25 b$, the rolling moment increment changed sign and became increasingly negative with further wing overlap. The rolling moment increments were

6 


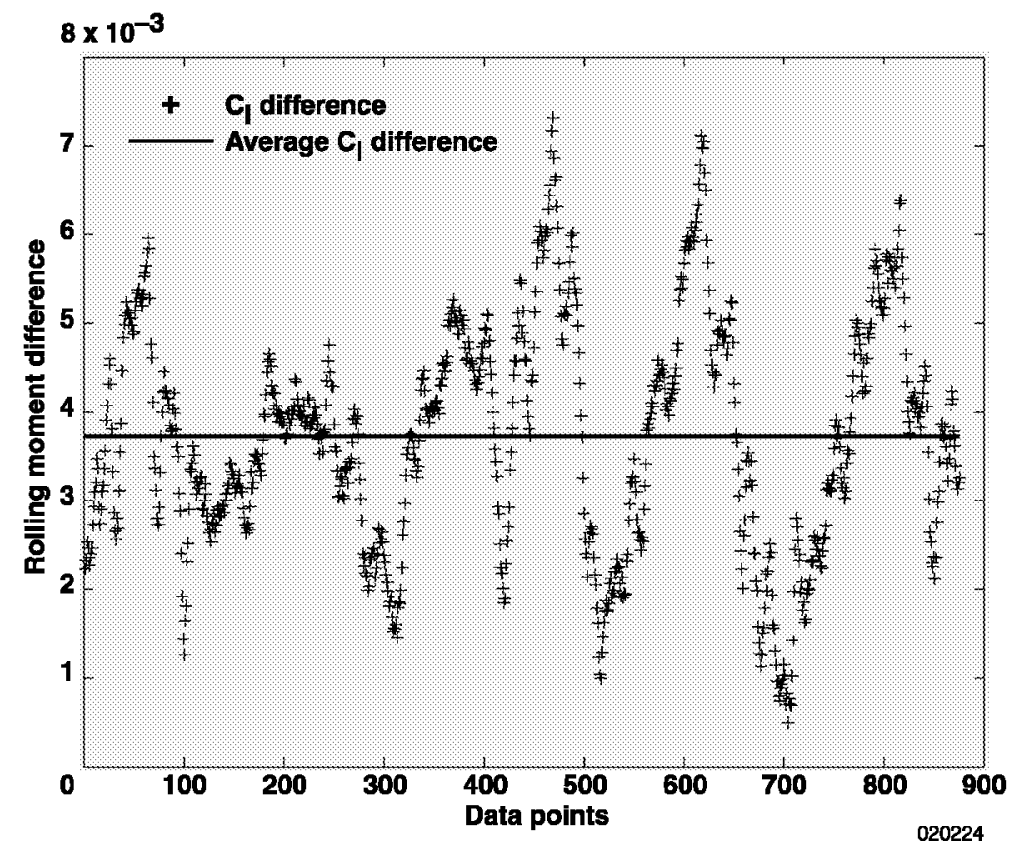

Figure 4. Example difference between vortex and free-flight models.

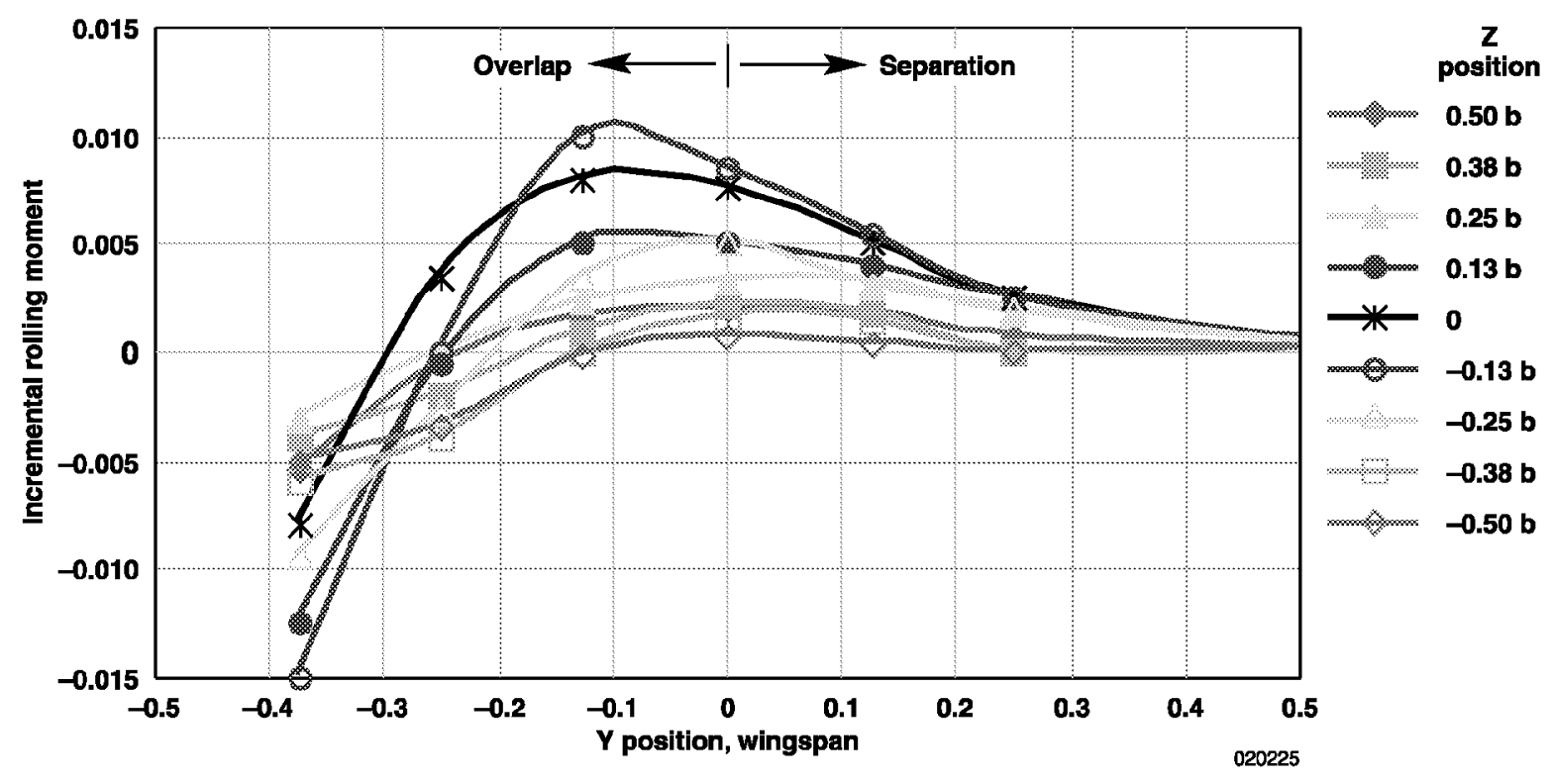

Figure 5. Incremental $C_{l}$ with lateral position at 55-ft nose-to-tail separation at Mach 0.56 and an altitude of 25,000 ft. 
greater for a formation airplane flying below the leading airplane, with the maximum value occurring at a vertical position of approximately $-0.13 \mathrm{~b}$. Note that this point also corresponds with the point of trimmed minimum drag. ${ }^{2}$ The vortex effect on the rolling increment at the $-0.13 b$ vertical position was similar to that at the level position. The vortex effect was significantly weaker for all other vertical positions. The pilots generally were able to compensate for the vortex-induced rolling moments increments using less than 15 percent of their control stick authority.

\section{Incremental Yawing Moment}

Starting at the same altitude and moving to the left from behind and right of the leader, the trailing airplane yawing moment increment increased in a nose-right direction to a maximum value when the wingtips were aligned (fig. 6). The vortex-induced yawing moment increment at $-0.25 \quad b$ became nose-left at a shared-altitude vertical position. Pilots referred to the flying qualities at $-0.25 b$ as "squirrelly" because both the rolling and yawing moment increments reversed direction with a small change in lateral position. At $0.38 b$ wing overlap, the nose-left yawing moment increment was eight times the value of the largest nose-right yawing moment increment, but at a position only $15 \mathrm{ft}$ further to the left.

Maintaining position was especially difficult in regions that had a large rate of change of the yawing moment increment with lateral position (that is, greater than $0.25 \mathrm{~b}$ overlap). Additionally, the pilots noted that the variation in sign of yawing moment increment with vertical position (for example, $Y=0$ in fig. 6) further complicated the task. As noted in the rolling moment data, the greatest effect was observed at the $-0.13 b$ vertical position.

\section{Incremental Pitching Moment}

The trailing airplane experienced an increasing nosedown pitching moment increment as wingtip overlap increased to $0.10 \quad b$ at the level vertical position (fig. 7). With more overlap, the pitching moment increment eventually became noseup. The largest nosedown effects were observed at the level vertical position. Although the effect at a vertical position of $-0.13 b$ was similar to the effect at a level position, the pitching moment increment was more noseup with wing overlap. These trends held true for almost all vertical positions, and the vortex effect became more benign as the vertical distance increased. The pitching moment increment reversal

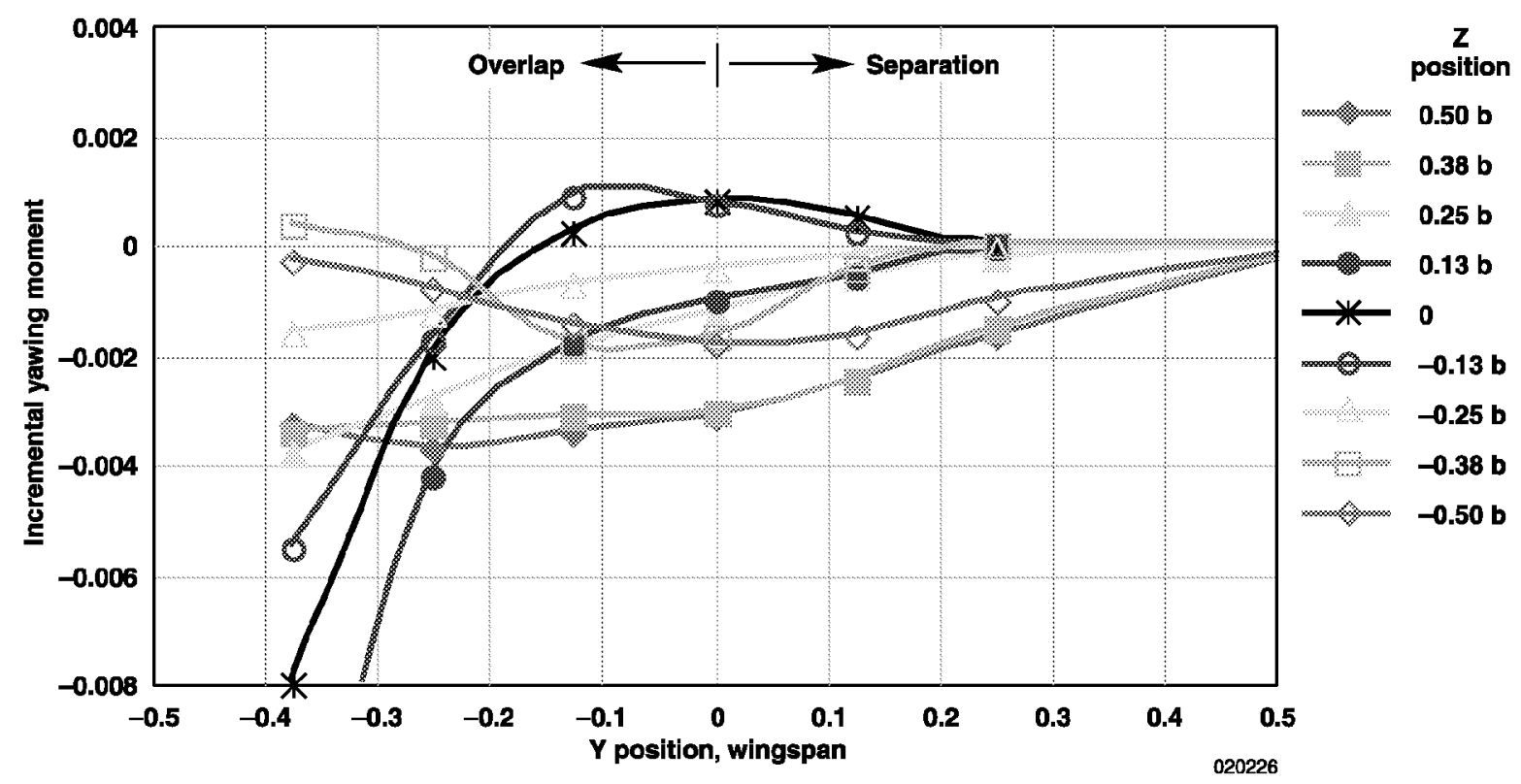

Figure 6. Incremental $C_{n}$ with lateral position at 55-ft nose-to-tail separation at Mach 0.56 and an altitude of $25,000 \mathrm{ft}$ 


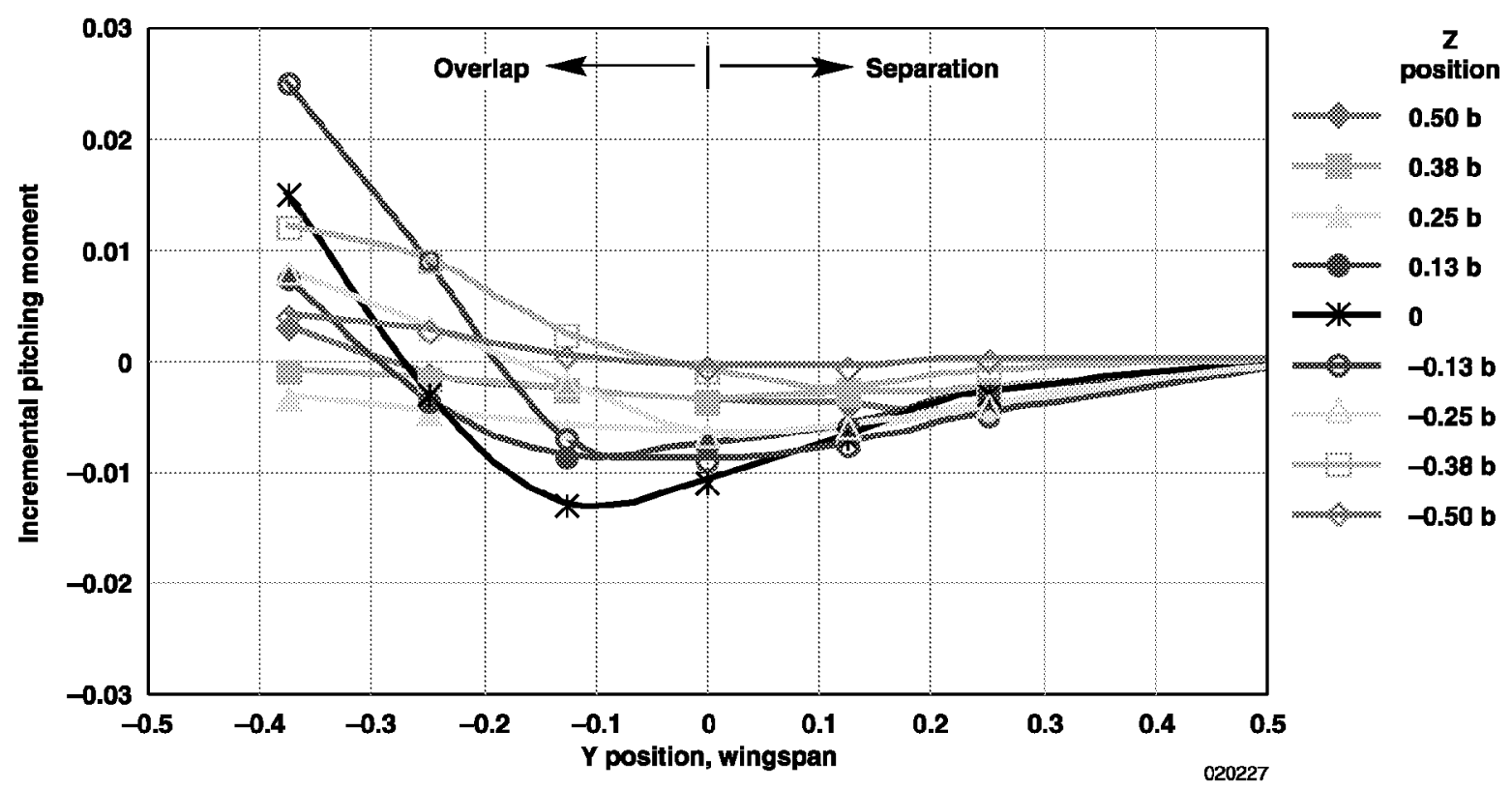

Figure 7. Incremental $C_{m}$ with lateral position at 55-ft nose-to-tail separation at Mach 0.56 and an altitude of $25,000 \mathrm{ft}$.

occurred at approximately $0.30 \mathrm{~b}$ wing overlap for the level and $0.13 \quad b$ vertical positions. The pilots commented that they did not have difficulty adapting to the varying pitch effects.

\section{Incremental Side Force}

Starting at the same altitude and moving to the left from behind and to the right of the leading airplane, the trailing airplane encountered a side force increment to the right (fig. 8). With increasing wing overlap, the side force increment steadily became more to the right, increasing rapidly as the wing overlap approached $0.40 \mathrm{~b}$. Like the moments, the greatest transients in side force increment were encountered when level or nearly level $( \pm 0.13 b)$ with the leading airplane. At positions with significant wing overlap, the incremental side force became very sensitive to position, most likely as a result of the vortex interaction with the fuselage and vertical tails of the trailing airplane.

\section{0-ft Nose-to-Tail Separation at the Subsonic Condition}

The aircraft were flown again at the same flight condition, but this time with a nose-to-tail separation of $110 \mathrm{ft}$. Flight test results again are given for incremental rolling, yawing, and pitching moments and side force.

\section{Incremental Rolling Moment}

The incremental rolling moments at $110-\mathrm{ft}$ nose-to-tail separation had the same shape as those at 55-ft, but the peak values tended to be less (fig. 9). As in the previous condition, the vertical positions at altitudes with or closely below the leading airplane received the greatest effect. Of note is the variation in incremental rolling moment for the $-0.25 b$ vertical position. After peaking at the $0.13 b$ lateral position, the right rolling moment increment rapidly degraded to a much stronger left rolling moment increment within $10 \mathrm{ft}$ of lateral position.

\section{Incremental Yawing Moment}

A few differences exist in yawing moment increment between $55-\mathrm{ft}$ and $110-\mathrm{ft}$ nose-to-tail separation. The peak nose-right values for the $0.13 \mathrm{~b}$ and all low vertical positions are significantly larger (positive) at $110-\mathrm{ft}$ (fig. 10) than at 55-ft nose-to-tail separation. The corresponding peak values also occurred further inboard than they did at 55-ft. The yawing moment increment at the level vertical position did not change much from 55-ft to 110-ft nose-to-tail separation. Also of note is the shape of the yawing moment increments with large wingtip overlap, as the values remained as variable as those at 55-ft nose-to-tail separation. 


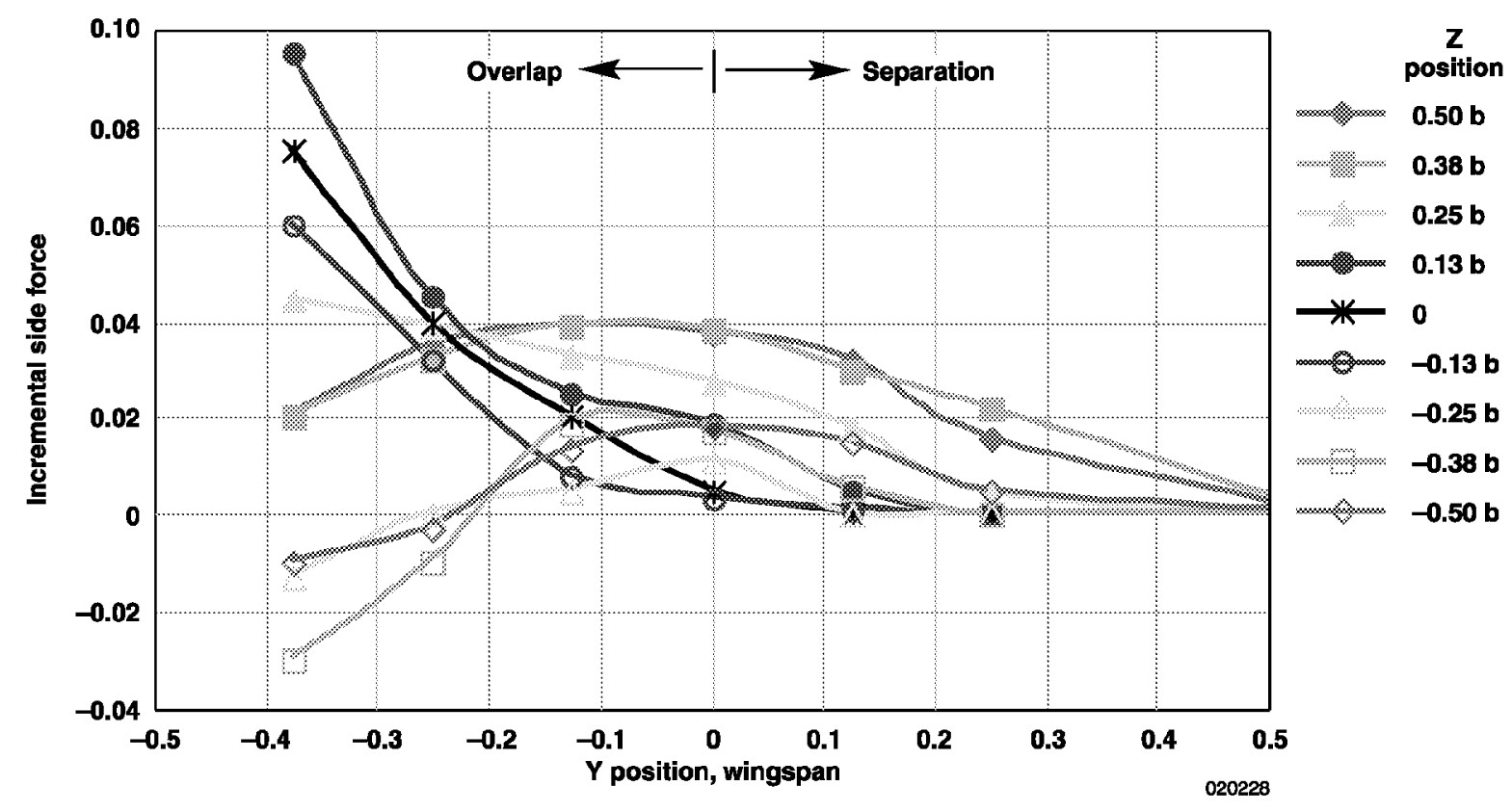

Figure 8. Incremental $C_{Y}$ with lateral position at 55-ft nose-to-tail separation at Mach 0.56 and an altitude of $25,000 \mathrm{ft}$.

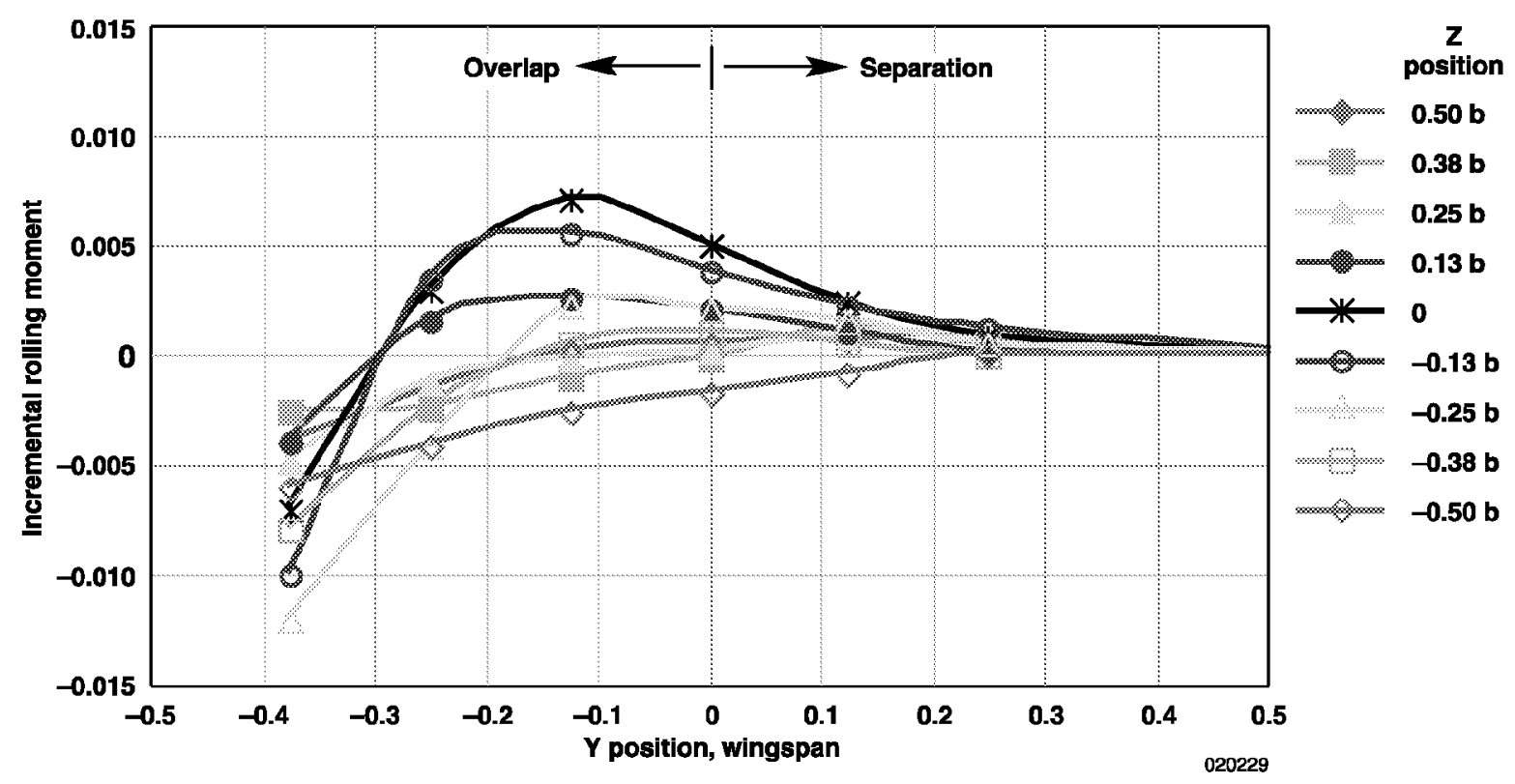

Figure 9. Incremental $C_{l}$ with lateral position at 110 -ft nose-to-tail separation at Mach 0.56 and an altitude of $25,000 \mathrm{ft}$. 


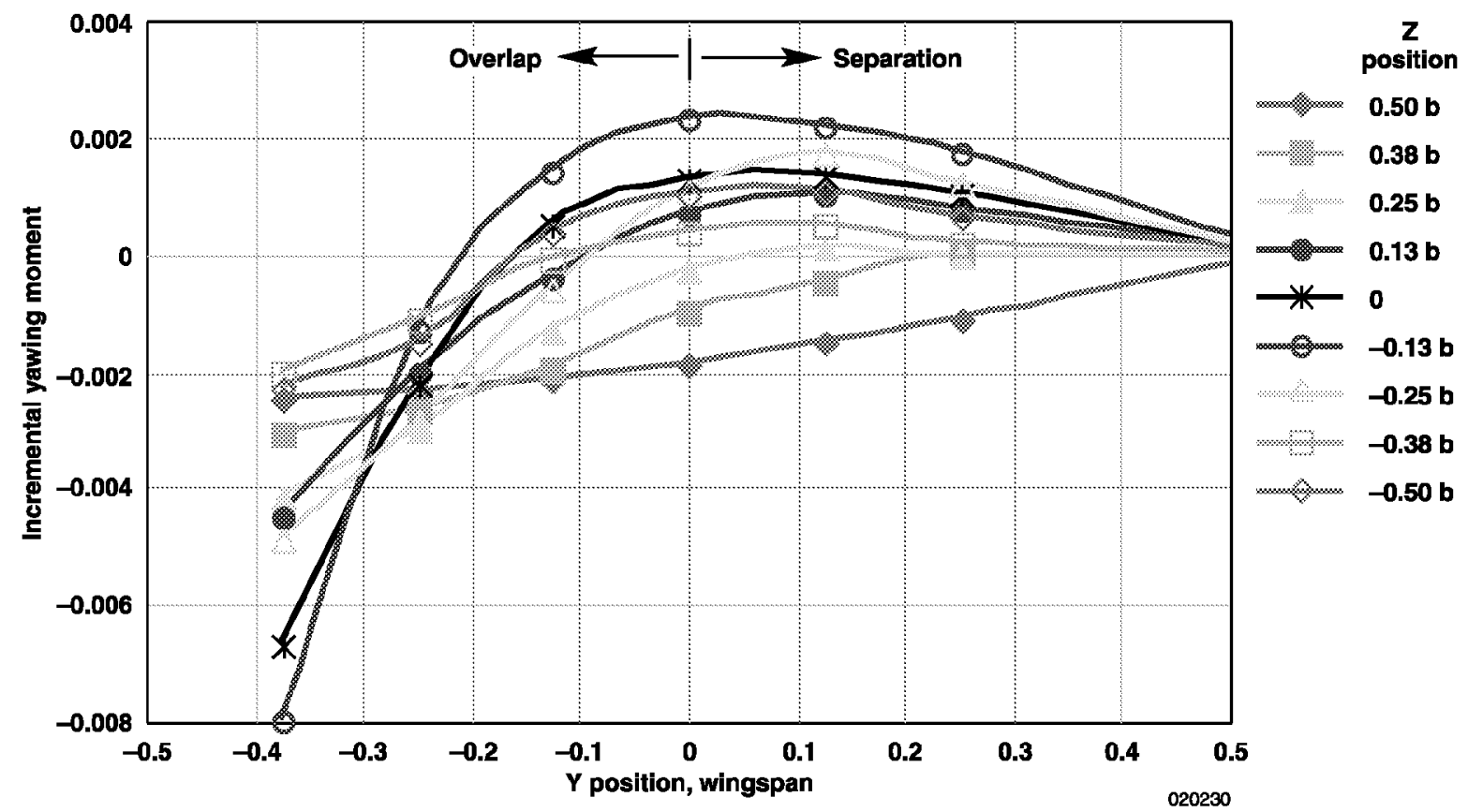

Figure 10. Incremental $C_{n}$ with lateral position at $110-\mathrm{ft}$ nose-to-tail separation at Mach 0.56 and an altitude of $25,000 \mathrm{ft}$.

\section{Incremental Pitching Moment}

With more longitudinal distance between the aircraft, the vortex effects on the incremental pitching moment were approximately the same (fig. 11). The vortex effect on the incremental pitching moment for the level and $-0.13 b$ vertical positions is slightly less near the lateral position for minimum drag, or $Y=-0.13 b$.

\section{Incremental Side Force}

The vortex had a greater effect on the side force increment at 110 -ft (fig. 12) than at 55-ft nose-to-tail separation. For the lower vertical positions, the side force increment was consistently to the left over the range of lateral positions. Conversely, the side force increment for the higher vertical positions was consistently to the right over the same lateral range. The exceptions were side force increments at the level and $\pm 0.13 b$ vertical positions. The side force increments at these positions peaked in a leftward direction at the $0.13 \mathrm{~b}$ lateral position, then increased steadily in a rightward direction as wing overlap increased.

\section{5-ft Nose-to-Tail Separation at the Transonic}

\section{Condition}

The aircraft were again flown with a nose-to-tail separation of $55 \mathrm{ft}$, but this time at a transonic flight condition of Mach 0.86 and an altitude of $36,000 \mathrm{ft}$. The following sections discuss flight test results for incremental rolling, yawing, and pitching moments and side force.

\section{Incremental Rolling Moment}

The rolling moment increment trends at the transonic condition have the same shape as those at the subsonic condition for 55-ft nose-to-tail separation, but the peak values for the level and $-0.13 b$ vertical positions are slightly smaller (fig. 13). With significant wing overlap, the rolling moment increments at the transonic conditions were less transient than at the subsonic condition. Overall, the vortex effects on the incremental rolling moment were weaker at the transonic condition.

\section{Incremental Yawing Moment}

The trends of the incremental yawing moment at the transonic condition and 55-ft nose-to-tail separation are significantly more uniform than those at the subsonic condition (fig. 14). Of note are the $-0.13 b$ and $0.50 b$ vertical positions. Their corresponding peak values most closely follow the trends at the subsonic condition. The vortex effects on the incremental yawing moment were weaker at the transonic condition. 


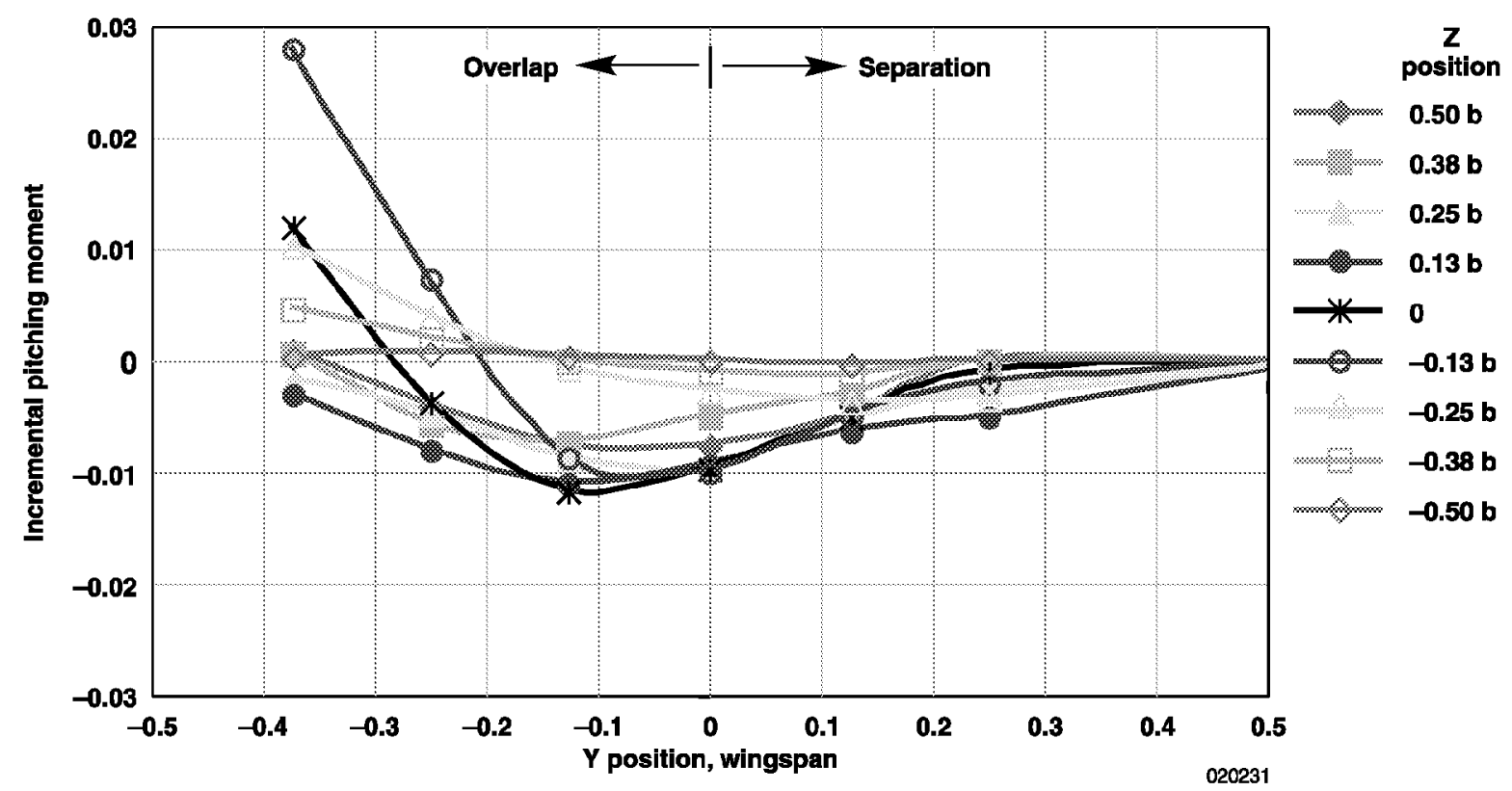

Figure 11. Incremental $C_{m}$ with lateral position at 110 -ft nose-to-tail separation at Mach 0.56 and an altitude of $25,000 \mathrm{ft}$.

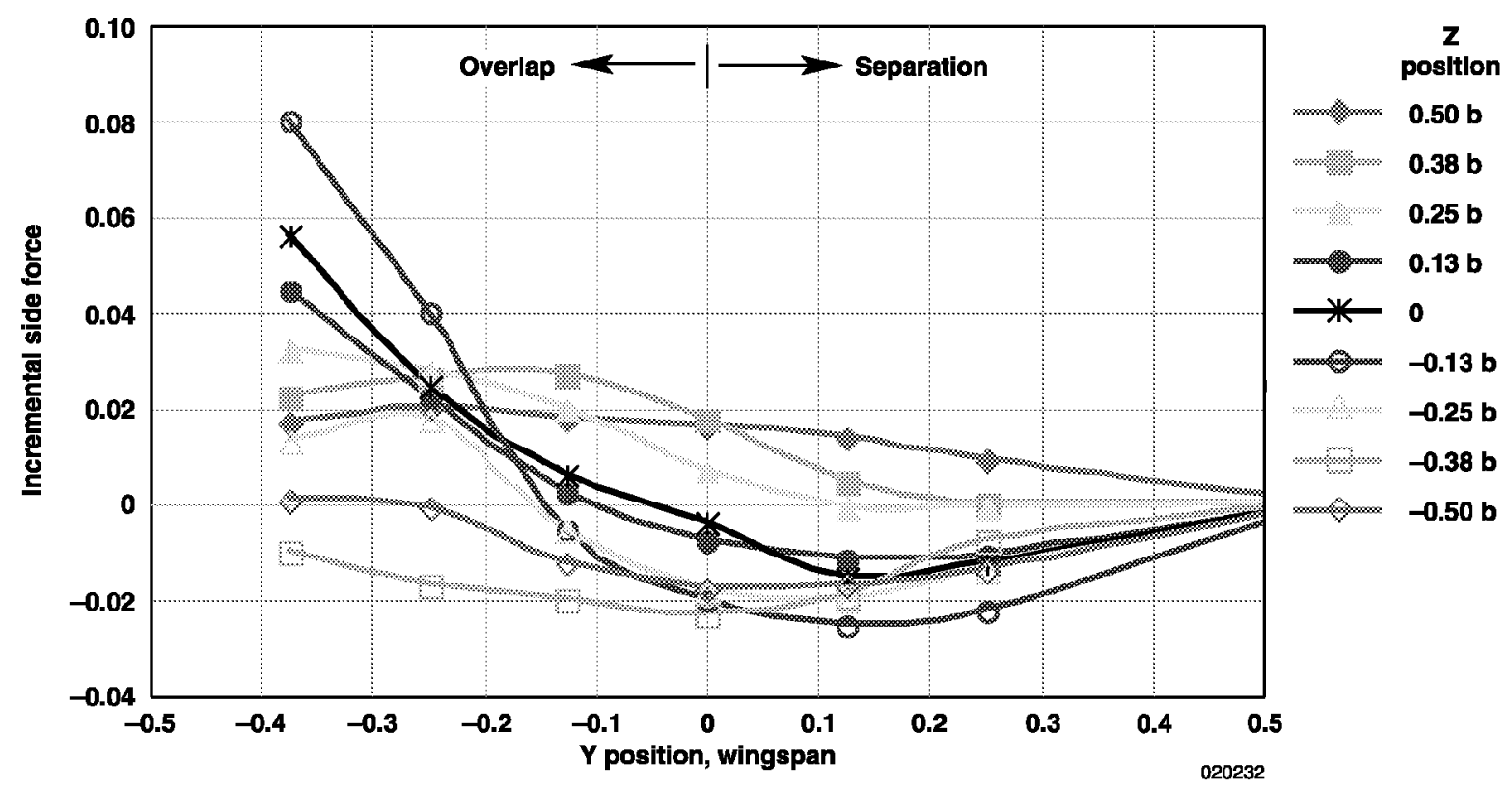

Figure 12. Incremental $C_{Y}$ with lateral position at 110 -ft nose-to-tail separation at Mach 0.56 and an altitude of $25,000 \mathrm{ft}$. 


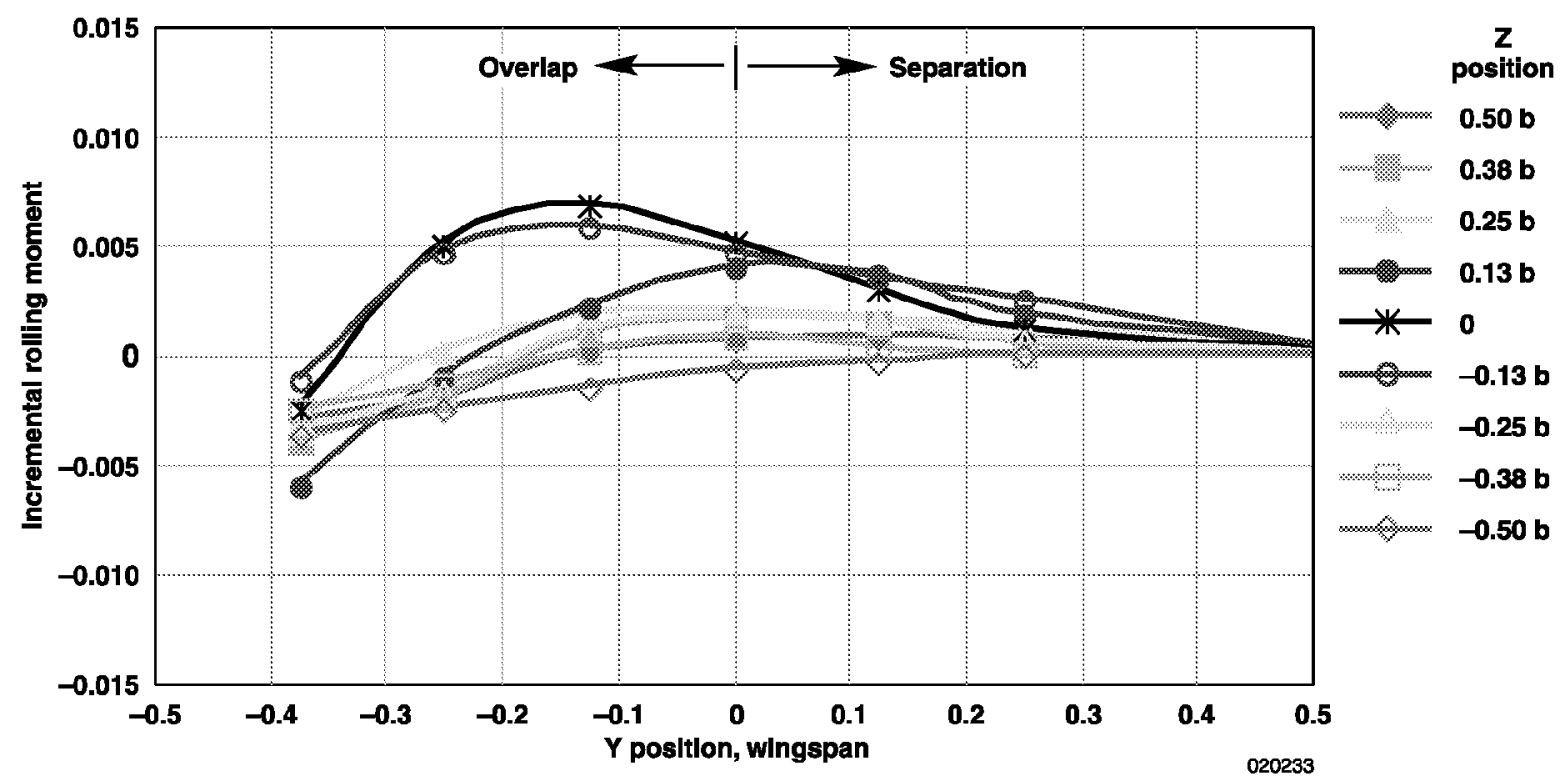

Figure 13. Incremental $C_{l}$ with lateral position at 55-ft nose-to-tail separation at Mach 0.86 and an altitude of $36,000 \mathrm{ft}$.

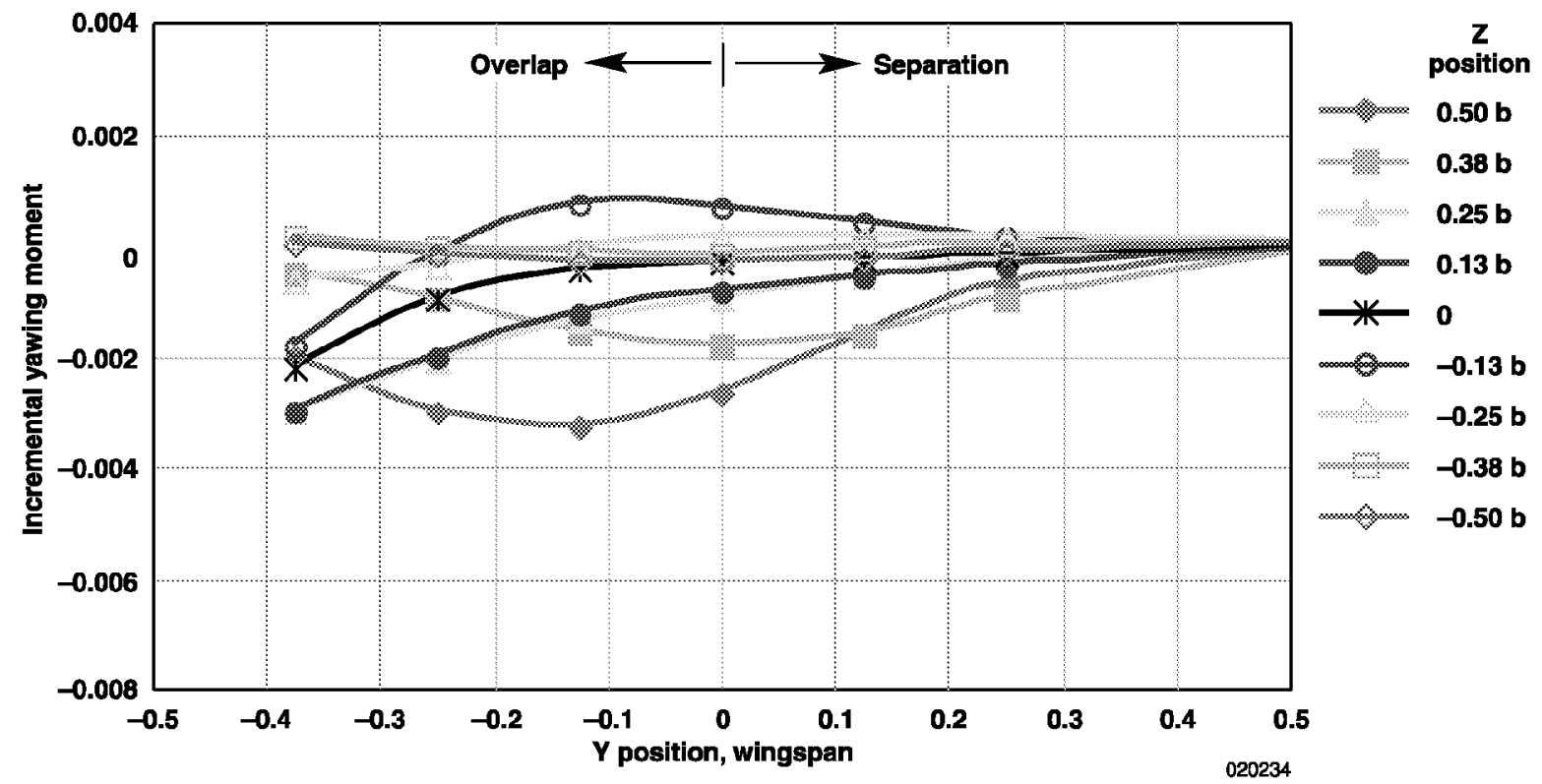

Figure 14. Incremental $C_{n}$ with lateral position at 55-ft nose-to-tail separation at Mach 0.86 and an altitude of $36,000 \mathrm{ft}$. 


\section{Incremental Pitching Moment}

As with the subsonic condition, the vortex at the transonic condition had the most effect on the incremental pitching moment at the level and $\pm 0.13 \mathrm{~b}$ vertical positions (fig. 15), with slightly increased peak nosedown values for the latter. Although the effects on the incremental pitching moment induced a nosedown attitude for almost all the test points at this condition, the effects of the vortex diminish with increased vertical separation from the leading airplane.

\section{$\underline{\text { Incremental Side Force }}$}

The side force increment was much more benign at this flight condition and nose-to-tail distance, and remained nearly zero for virtually all extreme high and low vertical positions (fig. 16). The level, $\pm 0.13 b$, and $0.25 b$ vertical positions yielded a rightward direction with wing overlap, similar to the trends at the subsonic flight condition but not as severe. 110-ft Nose-to-Tail Separation at the Transonic

\section{Condition}

The aircraft were flown again at the transonic condition, but this time with a nose-to-tail separation of $110 \mathrm{ft}$. Results again are discussed for incremental rolling, yawing, and pitching moment and side force.

\section{Incremental Rolling Moment}

At 110-ft nose-to-tail separation, the vortex effect on the incremental rolling moment of the trailing airplane at the transonic condition (fig. 17) was very similar to that at the subsonic condition. For all high vertical positions, the peak right rolling moment increments occurred further outboard than at the subsonic condition. At the $0.25 b$ lateral position, the vortex had a greater effect on the $0.13 b$ and $0.25 b$ vertical positions at the transonic conditions than at the subsonic condition. The greatest effects were at the level and $-0.13 b$ vertical positions.

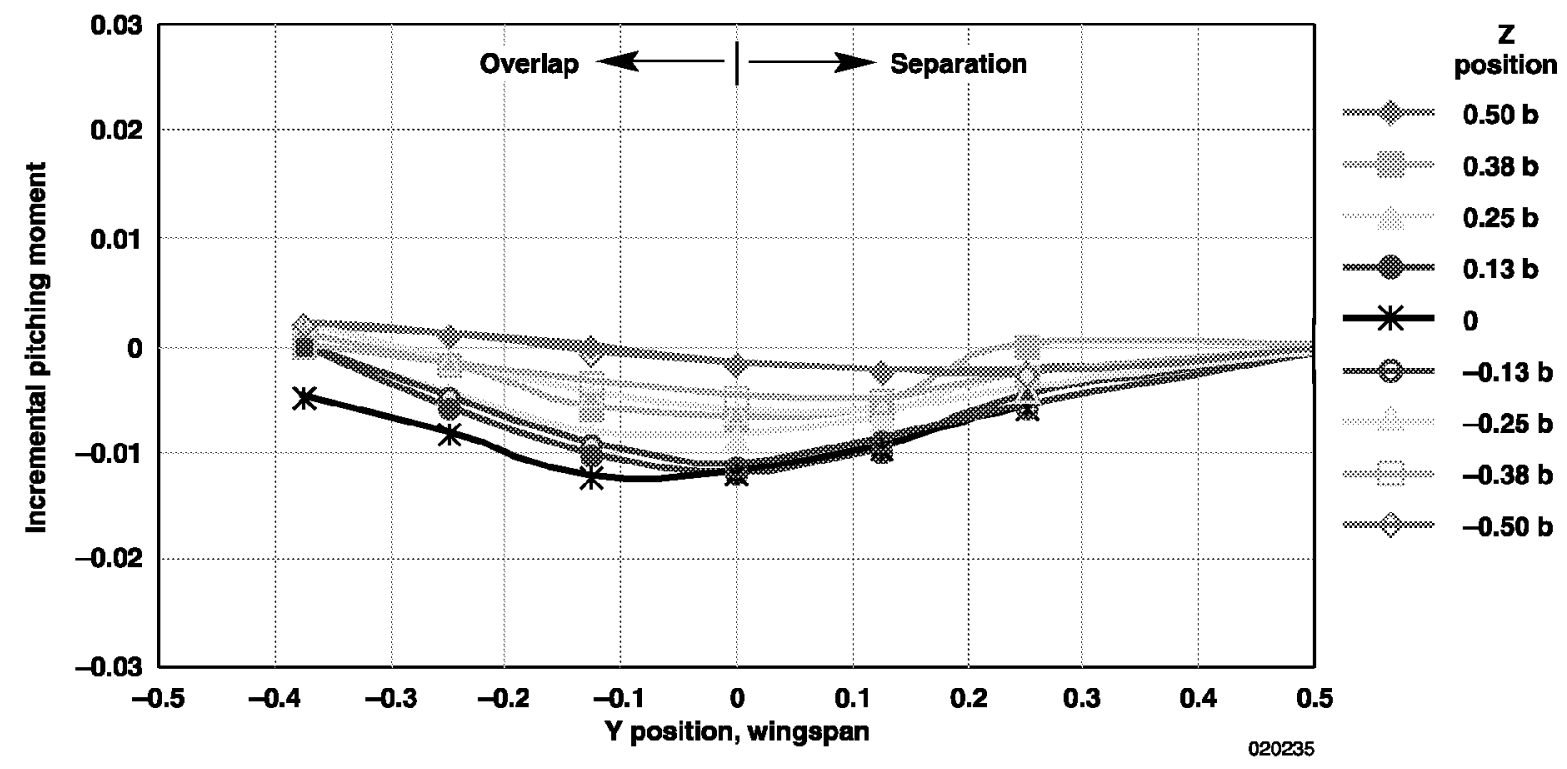

Figure 15. Incremental $C_{m}$ with lateral position at 55-ft nose-to-tail separation at Mach 0.86 and an altitude of $36,000 \mathrm{ft}$.

14

American Institute of Aeronautics and Astronautics 


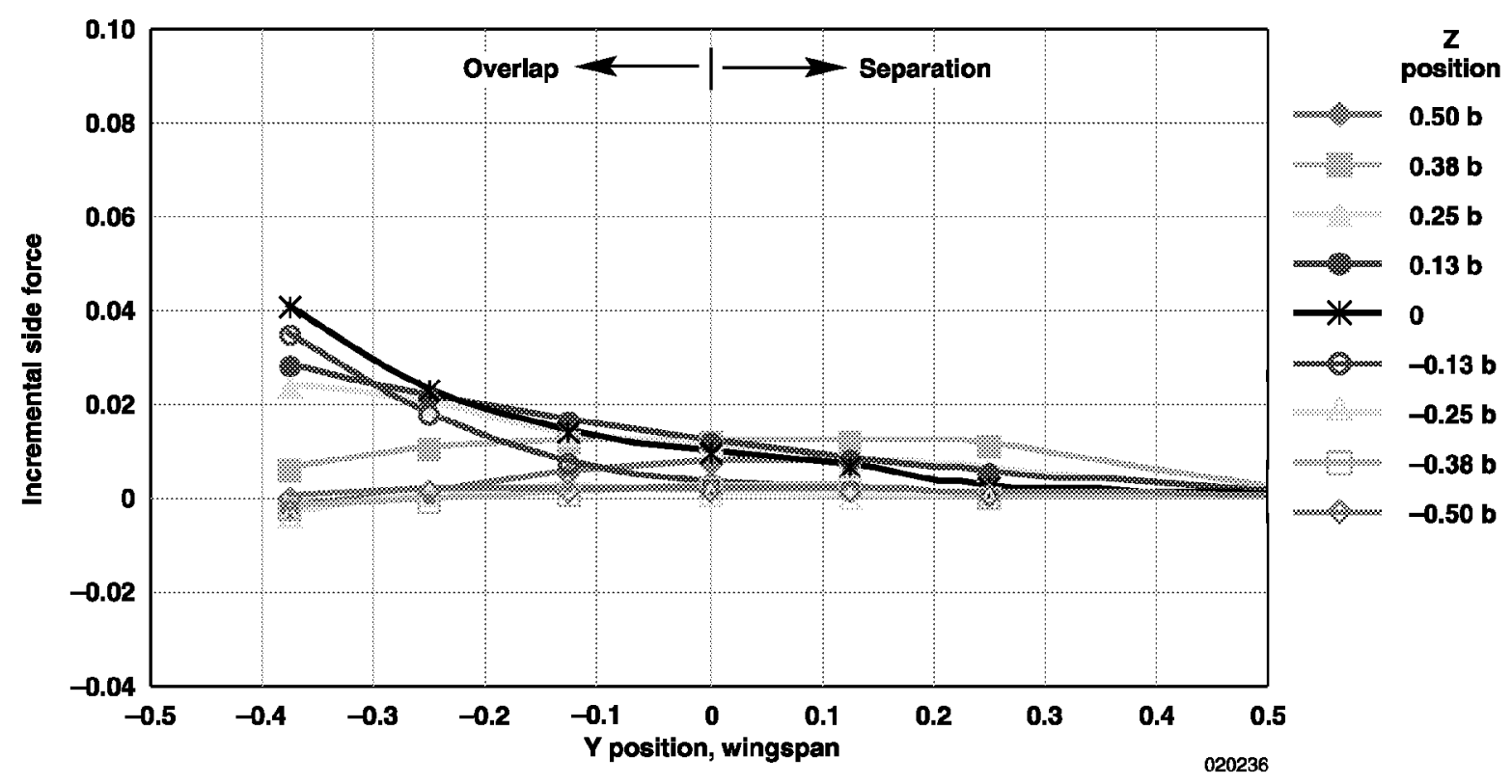

Figure 16. Incremental $C_{Y}$ with lateral position at 55-ft nose-to-tail separation at Mach 0.86 and an altitude of $36,000 \mathrm{ft}$.

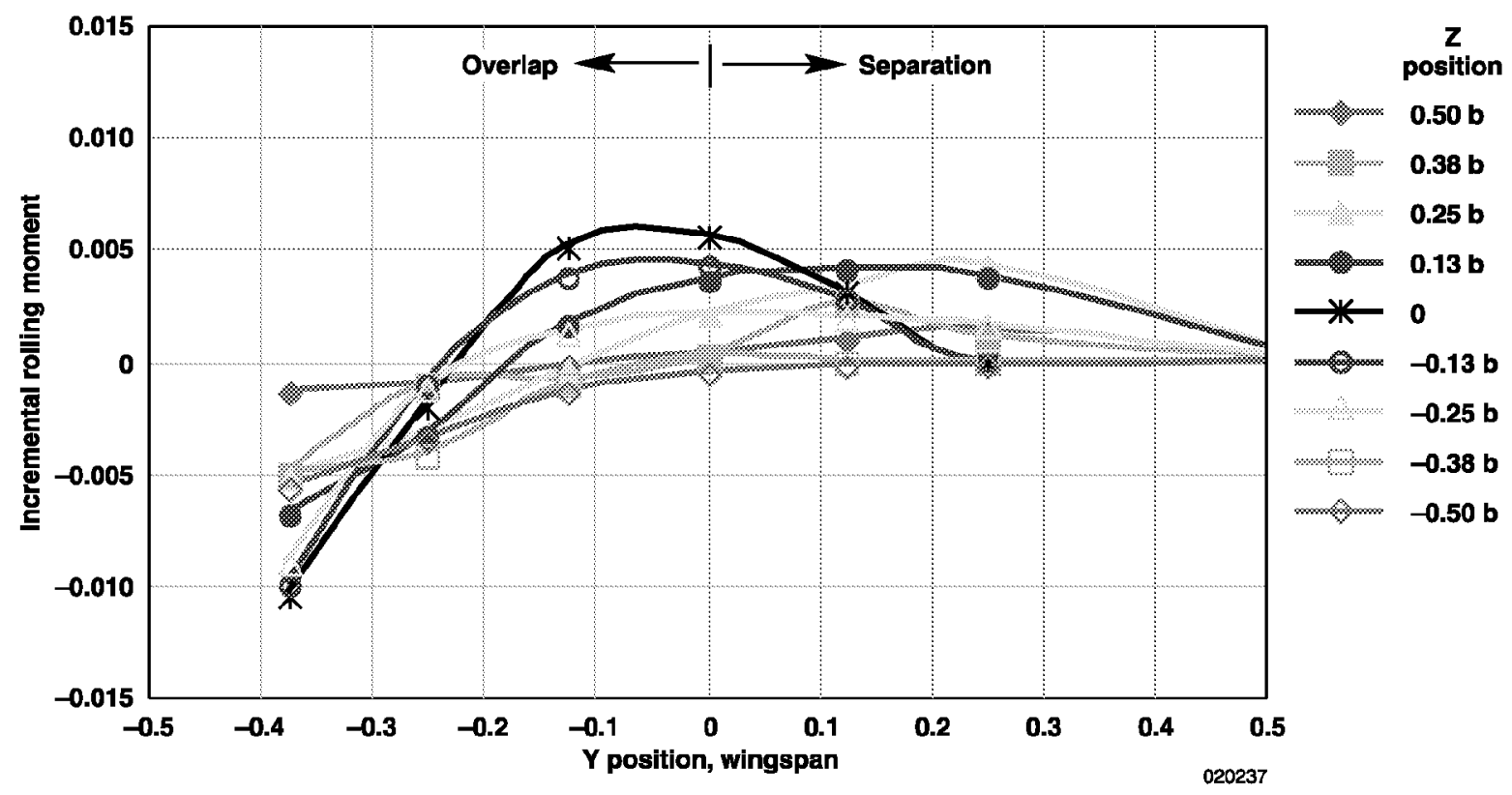

Figure 17. Incremental $C_{l}$ with lateral position at $110-\mathrm{ft}$ nose-to-tail separation at Mach 0.86 and an altitude of $36,000 \mathrm{ft}$. 


\section{Incremental Yawing Moment}

For the yawing moment increment, a few differences existed between the vortex effects at the subsonic and transonic condition (110-ft nose-to-tail separation). As wing overlap increased, the peak values at the level and $\pm 0.13 b$ vertical positions varied greatly and were characterized by steep nose-left gradients with more than 20-percent wing overlap (fig. 18). At approximately 25 -percent overlap, the yawing moment increments at the $0.13 b$ and level vertical positions reversed direction; this reversal is not evident from data at any other flight condition or test point. The vortex effects were weaker with significant wing overlap for almost all vertical positions. Overall, the vortex had a greater effect on the yawing moment increment at the transonic condition and 110-ft nose-to-tail separation.

\section{Incremental Pitching Moment}

Little difference exists between the two flight conditions for the pitching moment increment. The trends were the same at the transonic condition, but the pitching moment increment for all vertical positions was nosedown with less than 20 percent of wing overlap, and noseup as wing overlap increased (fig. 19). Of note are the peak noseup values for the level and $\pm 0.13 b$ vertical positions, as they are much closer in value than at the subsonic condition.

\section{Incremental Side Force}

Like the yawing moment increment, the side force increment caused by the vortex effect at the transonic condition was much less uniform at the middle vertical positions when compared with the results from the subsonic condition (fig. 20). The vortex had the most effect on the level and $0.13 b$ vertical positions. When level with or $0.13 b$ above the leading airplane, the side force increment changed direction from left to right at 25-percent wing overlap (fig. 20). This change might be caused by the vortex impingement on the fuselage and vertical tails. The influence on the other vertical positions was slightly reduced.

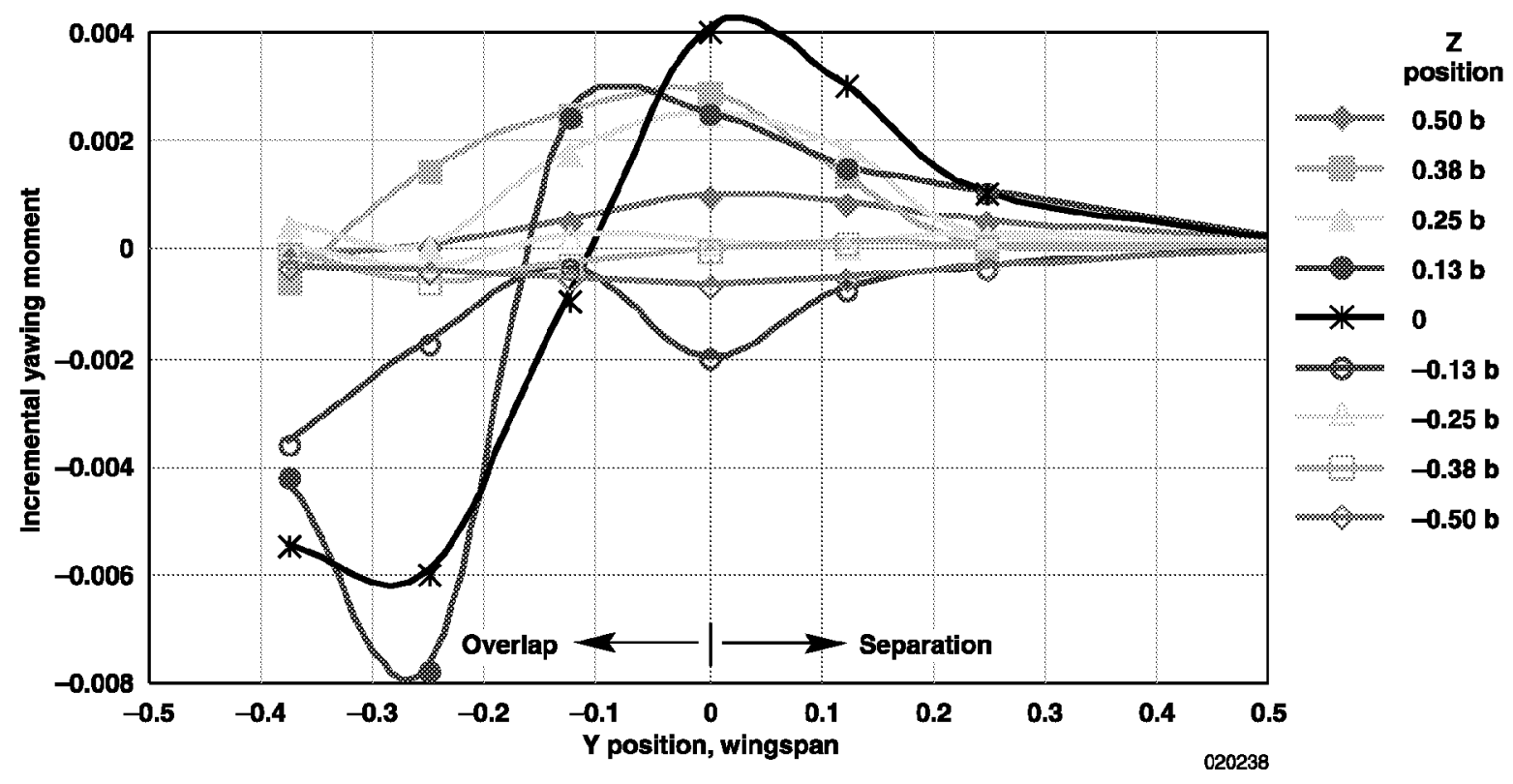

Figure 18. Incremental $C_{n}$ with lateral position at $110-\mathrm{ft}$ nose-to-tail separation at Mach 0.86 and an altitude of $36,000 \mathrm{ft}$ 


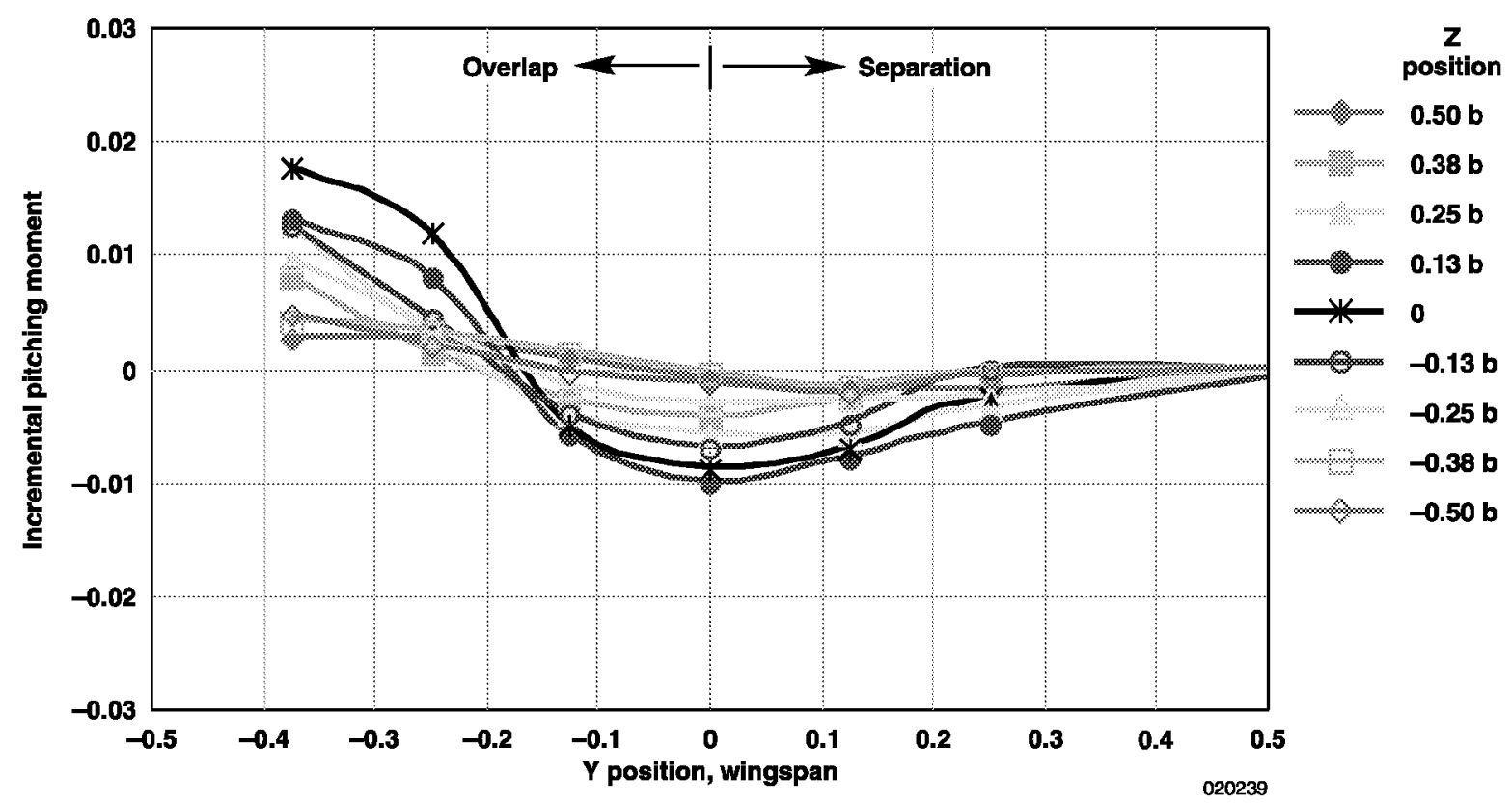

Figure 19. Incremental $C_{m}$ with lateral position at 110 -ft nose-to-tail separation at Mach 0.86 and an altitude of $36,000 \mathrm{ft}$.

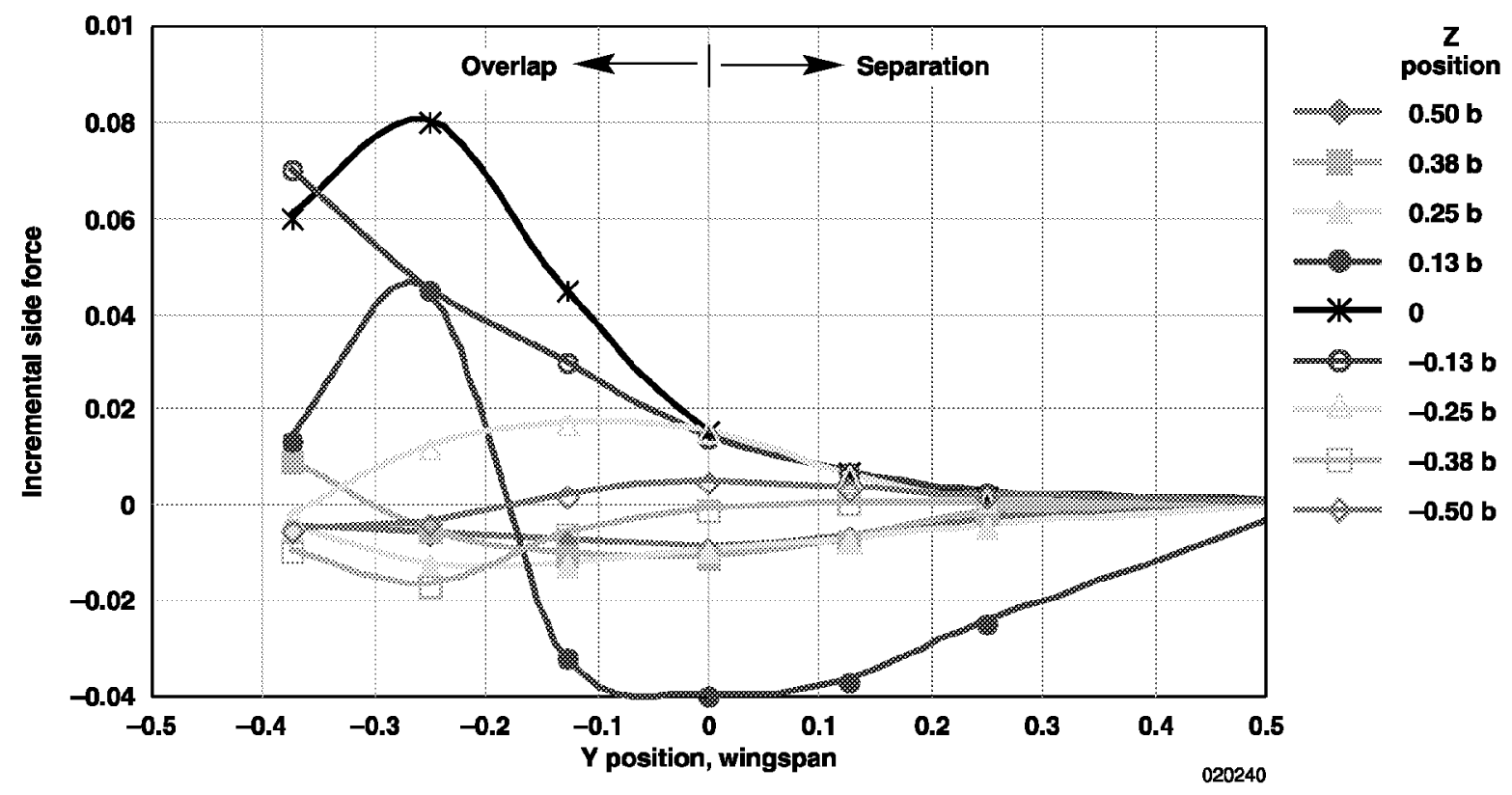

Figure 20. Incremental $C_{Y}$ with lateral position at 110 -ft nose-to-tail separation at Mach 0.86 and an altitude of $36,000 \mathrm{ft}$. 


\section{Concluding Remarks}

In-flight measurements of the side force and moment on a trailing F/A-18 airplane induced by the wingtip vortex of a leading F/A-18 airplane were obtained. These flight tests demonstrated that nearly all vortex-induced effects are easily compensable by the pilot. The vortex mapping completed in this series of flight tests showed that the incremental side force and moments have multiple peaks, and the sensitivity to position in the formation changes with flight condition and nose-to-tail distance.

The vortex-induced incremental side force and moments first peaked at a lateral position of 13-percent wing overlap and vertical positions of level and 13-percent below the leading airplane. These peak vortex effects were coincident with the position for maximum drag reduction, and the incremental force and moments were more sensitive to formation position further inboard of these peaks.

The flight data suggest the vortex effects with increased longitudinal distance were weaker in pitch and roll, but stronger in yaw and side force. At 55-ft nose-to-tail separation, vortex effects at transonic conditions were weaker than those encountered at subsonic conditions. At transonic conditions and 110-ft nose-to-tail separation, vortex effects were weaker in pitch and roll but stronger in yaw and side force compared with the effects at subsonic conditions. Although the vortex effects on the trailing airplane were found to peak in the area of maximum drag reduction, these effects were well within the capability of the pilot; and therefore, the aerodynamic effects did not appear to jeopardize the success of a formation flight controller design for this type of aircraft.

The fact that moment peaks corresponded with the areas of maximum drag reduction poses obvious issues for an autonomous flight control system. The control system must be robust enough to handle the sensitive moment changes that occur in the area of 13-percent wingtip overlap and 13-percent below the leading airplane. The system must also be precise enough to maintain position to the degree that all fuel savings are not lost to position maintenance, trim drag, and constant throttle changes.

Although the largest moments occurred with significant wing overlap, the control system must remain stable in this very transient environment to achieve maximum fuel savings. A control system for a possible commercial application must also be able to handle an inadvertent position change without injuring passengers. This database can be used for further study of autonomous formation flight control system design and flying quality analysis, and for determining if aerodynamic prediction codes can reliably estimate these effects for future applications.

\section{$\underline{\text { References }}$}

${ }^{1}$ Weimerskirch, Henri, Julien Martin, Yannick Clerquin, Peggy Alexandre, and Sarka Jiraskova, "Energy Saving in Flight Formation," Nature, vol. 413, Oct. 18, 2001, pp. 697-698.

${ }^{2}$ Vachon, M. Jake, Ronald J. Ray, Kimberly Ennix, and Kevin Walsh, "Measured Performance Benefits During the Autonomous Formation Flight Program," To be presented at the AIAA Atmospheric Flight Mechanics Conference, AIAA-2002-4491, Aug. 2002.

${ }^{3}$ Hummel, D., "The Use of Aircraft Wakes to Achieve Power Reductions in Formation Flight" AGARD CP-584, May 1996, pp. 36-1-36-13.

${ }^{4}$ Dunn, Ken, Calculated Aerodynamic Force and Moment Increments Induced on the Trailing Aircraft in a Two-Aircraft F-18 Formation, Boeing North American, Inc., Long Beach, California, 1999. (Distribution restricted to AFF program participants.)

${ }^{5}$ Bever, Glenn, Peter Urschel and Curtis E. Hanson, Comparison of Relative Navigation Solutions Applied Between Two Aircraft, NASA/TM-2002-210728, July 2002. Also presented at the AIAA First Technical Conference and Workshop on Unmanned Aerospace Vehicles, Systems, Technologies and Operations, Portsmouth, Virginia, 20-23 May 2002.

${ }^{6}$ Gainer, Thomas G. and Sherwood Hoffman, Summary of Transformation Equations and Equations of Motion Used in Free-Flight and Wind-Tunnel Data Reduction and Analysis, NASA SP-3070, 1972.

${ }^{7}$ Maine, Richard E. and Kenneth W. Iliff, Application of Parameter Estimation to Aircraft Stability and Control - The Output-Error Approach, NASA RP-1168, 1986. 
Public reporting burden for this collection of information is estimated to average 1 hour per response, including the time for reviewing instructions, searching existing data sources, gathering and maintaining the data needed, and completing and reviewing the collection of information. Send comments regarding this burden estimate or any other aspect of this collection of information, including suggestions for reducing this burden, to Washington Headquarters Services, Directorate for Information Operations and Reports, 1215 Jefferson Davis Highway, Suite 1204 , Arlington, VA 22202-4302, and to the Office of Management and Budget, Paperwork Reduction Project (0704-0188), Washington, DC 20503.

\begin{tabular}{|l|l|l|}
\hline 1. AGENCY USE ONLY (Leave blank) & $\begin{array}{l}\text { 2. REPORT DATE } \\
\text { August } 2002\end{array}$ & $\begin{array}{l}\text { 3. REPORT TYPE AND DATES COVERED } \\
\text { Technical Memorandum }\end{array}$ \\
\hline
\end{tabular}

4. TITLE AND SUBTITLE

Induced Moment Effects of Formation Flight Using Two F/A-18 Aircraft

6. AUTHOR(S)

$7065500 \mathrm{E} 82800 \mathrm{AFF}$

Jennifer L. Hansen and Brent R. Cobleigh

7. PERFORMING ORGANIZATION NAME(S) AND ADDRESS(ES)

8. PERFORMING ORGANIZATION

REPORT NUMBER

NASA Dryden Flight Research Center

P.O. Box 273

Edwards, California 93523-0273

H-2502

9. SPONSORING/MONITORING AGENCY NAME(S) AND ADDRESS(ES)

10. SPONSORING/MONITORING

AGENCY REPORT NUMBER

National Aeronautics and Space Administration

Washington, DC 20546-0001

NASA/TM-2002-210732

11. SUPPLEMENTARY NOTES

Also presented at the AIAA Atmospheric Flight Mechanics Conference and Exhibit, Monterey, CA, August 5-8, 2002.

12a. DISTRIBUTIONIAVAILABILITY STATEMENT

2b. DISTRIBUTION CODE

Unclassified-Unlimited

Subject Category 02

This report is available at http://www.dfrc.nasa.gov/DTRS/

13. ABSTRACT (Maximum 200 words)

Previous investigations into formation flight have shown the possibility for significant fuel savings through drag reduction. Using two F/A-18 aircraft, NASA Dryden Flight Research Center has investigated flying aircraft in autonomous formation. Positioning the trailing airplane for best drag reduction requires investigation of the wingtip vortex effects induced by the leading airplane. A full accounting of the vortex effect on the trailing airplane is desired to validate vortex-effect prediction methods and provide a database for the design of a formation flight autopilot. A recent flight phase has mapped the complete wingtip vortex effects at two flight conditions with the trailing airplane at varying distances behind the leading one. Force and moment data at Mach 0.56 and an altitude of $25,000 \mathrm{ft}$ and Mach 0.86 and an altitude of 36,000 ft have been obtained with $20,55,110$, and $190 \mathrm{ft}$ of longitudinal distance between the aircraft. The moments induced by the vortex on the trailing airplane were well within the pilot's ability to control. This report discusses the data analysis methods and vortex-induced effects on moments and side force. An assessment of the impact of the nonlinear vortex effects on the design of a formation autopilot is offered.

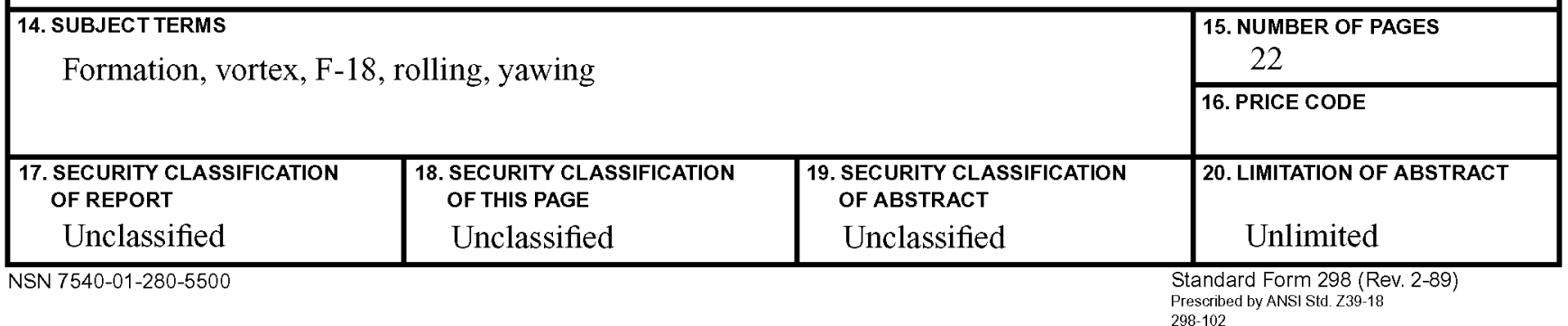

